\title{
On Similarity in Fuzzy Description Logics
}

\author{
Eva Armengol ${ }^{\mathrm{a}}$, Pilar Dellunde ${ }^{\mathrm{a}, \mathrm{b}, \mathrm{d}}$, Àngel García-Cerdaña ${ }^{\mathrm{a}, \mathrm{c}, *}$ \\ ${ }^{a}$ Artificial Intelligence Research Institute (IIIA-CSIC), Campus UAB, E-08193 Bellaterra, \\ Catalonia, Spain.

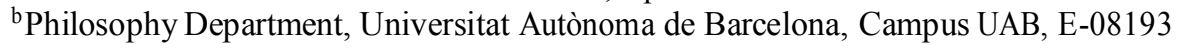 \\ Bellaterra, Catalonia, Spain \\ ${ }^{c}$ Information and Communication Technologies Department, University Pompeu Fabra, Tànger, \\ 122-140, E-08018 Barcelona, Catalonia, Spain. \\ ${ }^{\mathrm{d} B a r c e l o n a}$ Graduate School of Mathematics, Universitat Autònoma de Barcelona, Campus UAB, \\ E-08193 Bellaterra, Catalonia, Spain
}

\begin{abstract}
This paper is a contribution to the study of similarity relations between objects represented as attribute-value pairs in Fuzzy Description Logics. For this purpose we use concrete domains in the fuzzy description logic IALCEF(D) associated either with a left-continuous or with a finite t-norm. We propose to expand this fuzzy description logic by adding a Similarity Box (SBox) including axioms expressing properties of fuzzy equalities. We also define a global similarity between objects from similarities between the values of each object attribute (local similarities) and we prove that the global similarity defined using a t-norm inherits the usual properties of the local similarities (reflexivity, symmetry or transitivity). We also prove a result relative to global similarities expressing that, in the context of the logic MTL $\forall$, similar objects have similar properties, being these properties expressed by predicate formulas evaluated in these objects.
\end{abstract}

Keywords: Similarity Relation, Description Logics, Fuzzy Description Logics, Attribute-Value Representation, Similarity Box

\footnotetext{
${ }^{*}$ Corresponding author

Email addresses: eva@iiia.csic.es (Eva Armengol),pilar.dellunde@uab.cat (Pilar Dellunde), ange1@iiia.csic.es (Àngel García-Cerdaña)
} 


\section{Introduction}

Similarity has been a central issue for decades in different disciplines, ranging from philosophy (Leibniz's Principle of the Identity of Indiscernibles [33]) and psychology (Tversky's stimuli judged similarity [62]) to natural sciences (taxonomy [37]) and mathematics (geometric similarity [25, Chapter 4]).

In artificial intelligence (AI) similarity plays an important role because the analogy reasoning is behind some of the early machine learning methods. For instance, case-based reasoning methods (see [38]) are based on the principle that "similar problems have similar solutions". In clustering [39] objects are grouped in clusters according to their similarities. The key point of these methods is to define a similarity metrics to express the similarity between objects. In AI, domain objects are commonly represented using attribute-value pairs. Metrics used to assess the similarity between two objects have to take into account such representation, in order to do that, it is usual to consider the number of similar attributevalues. The global similarity between two objects has to be seen as an aggregation of the local similarities of the attributes describing them (see [43] for a collection of similarity measures; for the item of aggregation operators see [50,61]).

In the present paper we study how to deal with similarities when objects are represented by sets of attribute-value pairs in Fuzzy Description Logics. Description Logics (DLs) are knowledge representation languages built on the basis of classical logic. DLs allow the creation of knowledge bases and provide ways to reason on the contents of these bases. A full reference manual of the field can be found in [4]. Hirsh and Kudenko [42] proposed a way to apply feature-based learners to DL learning tasks by presenting a method to compute an attribute vector representation of DL instances. Although it is a work oriented to learning, the authors deal with the problem of how to represent attribute-value objects in DL, and they manage it by expressing each attribute as a concept.

Fuzzy Description Logics (FDLs) are natural extensions of DLs expressing vague concepts commonly present in real applications (see for instance $[9,45,56$, 57, 59, 60]). Hájek [36] proposed to deal with FDLs taking as basis t-norm based fuzzy logics. His aim was to enrich the expressive possibilities in FDLs and to capitalize on recent developments in the field of mathematical fuzzy logic. From this perspective, in [34] a family of FDL languages was defined. These languages include truth constants for representing truth degrees, thus allowing the definition of the axioms of the knowledge bases as sentences of a predicate fuzzy language in much the same way as in classical DLs.

In the fuzzy framework, the notion of similarity was introduced by Zadeh in 
[64] as a generalization of the notion of equivalence relation (see [53] for a historical overview on the notion of t-norm based similarity). As Zadeh pointed out, one of the possible semantics of fuzzy sets is in terms of similarity. Indeed, the membership degree of an object to a fuzzy set can be seen as the degree of resemblance between this object and prototypes of the fuzzy set. Ruspini suggests in [54] that the degree of similarity between two objects A and B may be regarded as the degree of truth of the vague proposition "A is similar to B". Thus, similarity among objects can be seen as a phenomenon essentially fuzzy. Following this idea, we want to use the capabilities of languages of FDLS to express similarity degrees between objects.

There are many authors that have focused on a fuzzy notion of similarity. In a more general context of predicate fuzzy logics, Hájek studied similarities and applied the obtained results to the analysis of fuzzy control [35]. Bělohlávek [19] presented a general theory of fuzzy relational systems. Model-theoretic properties of algebras with fuzzy equalities were studied in [24, 19]. Dubois and Prade pointed out in [28] that three main semantics for membership functions existed in the literature: similarity, preference and uncertainty. Each semantic underlying a particular class of applications. Similarity notions, for instance, have been exploited in clustering analysis and fuzzy controllers. The authors stated that the similarity semantics of fuzzy sets could serve as a basis for the estimation of preference and uncertainty.

In [20] Běhounek et al. studied fuzzy relations in the graded framework of Fuzzy Class Theory (FCT) generalizing existing crisp results on fuzzy relations to the graded framework. In FCT we can express the fact that a fuzzy relation is reflexive, symmetric or transitive up to a certain degree, and similarity is defined as a first-order sentence which is the fusion of three sentences corresponding to the graded notions of reflexivity, symmetry and transitivity. This allows to speak in a natural way of the degree of similarity of a relation. In [3] the relationship between global and local similarities in the graded framework of FCT was investigated.

Another interesting approach is the one taken by Bobillo and Straccia in [11]. The authors provide a simple solution to join two formalisms, fuzzy DLs and rough DLs, and define a fuzzy rough DL. This logic is more general than other related approaches, including tight and loose fuzzy rough approximations and being independent of the fuzzy logic operators considered. The key idea in rough set theory is the approximation of a vague concept by means of a pair of concepts, usually this approximation is based on an equivalence relation between elements of the domain. They extend this idea using fuzzy similarity relations instead of equivalence relations, giving raise to fuzzy rough sets. Bobillo and Straccia use a 
fixed set of similarities in order to introduce the semantics for the upper and lower approximation constructors. A revised and extended version of their work is [12].

Redarding the work done on distances defined from t-norms, in [2] Alsina introduced the idea of constructing distances from a t-norm and its dual. He proved that being a copula is a sufficient condition for the t-norm to induce a distance. Y. Ouyang in [52] gives an example of a continuous strict Archimedean t-norm that is not a copula and that generates a distance. An interesting problem recently solved in [1] (for the t-norms with the same zero region as Luckasiewicz) is the characterization of those $t$-norms that induce distances. The authors give a necessary and sufficient condition for a pair consisting of a t-norm and a t-conorm (not necessarily its dual) to generate a distance.

Our paper is a contribution to the study of similarity relations between objects represented as attribute-value pairs in Fuzzy Description Logics. It is organized as follows. In Section 2 we recall the notions and results from predicate fuzzy logics necessary to the understanding of the paper. In Sections 3 and 4 we recall the syntax and semantics of the classical description logic ALC and the fuzzy description logic IALCE. In Section 5 we expand the Fuzzy Description Language IALCE by introducing a similarity box (SBox) including axioms expressing properties of fuzzy equalities, allowing models of the language with a non-geometrical inter-

pretation of the similarity symbols. In the Similarity Box we express that a role is reflexive, symmetric, transitive or that it is a congruence. We also obtain some results stating the equivalence of these axioms with certain role inclusion axioms. In Section 6 we explain how the attribute-value representation can be captured in the framework of the classical description language ALC and of the fuzzy description language IALCEF by means of the so-called concrete domains. In the same section we define a global similarity between objects from similarities between the values of each object's attribute (local similarities) and we show that the global similarity inherits the usual properties of the local similarities (reflexivity, symmetry or transitivity). In Section 7 we generalize a result of [35] to the logic MTL $\forall$ relative to the global similarity. Finally there is a section devoted to concluding remarks and future work.

\section{Predicate fuzzy logics}

A triangular norm (or t-norm) [41] is a binary operation defined on the real interval $[0,1]$ satisfying the following properties: associative, commutative, non decreasing in both arguments, and having 1 as unit element. Given the usual order in $[0,1]$, a left-continuous t-norm $*$ is characterized by the existence of a unique 
operation $\Rightarrow_{*}$ satisfying, for all $\mathrm{x}, \mathrm{y}, \mathrm{z} \in[0,1]$, the condition

$$
\mathrm{x} * \mathrm{z} \leq \mathrm{y} \text { if and only if } \mathrm{z} \leq \mathrm{x} \Rightarrow_{\star} \mathrm{y} .
$$

This operation is called the residuum of the t-norm and it satisfies

$$
\mathrm{x} \Rightarrow_{\star} \mathrm{y}:=\max \{\mathrm{z}: \mathrm{x} * \mathrm{z} \leq \mathrm{y}\}
$$

A continuous t-norm is a left-continuos t-norm satisfying the so-called divisibility condition: for all $\mathrm{x}, \mathrm{y} \in[0,1], \min \{\mathrm{x}, \mathrm{y}\}=\mathrm{x} *\left(\mathrm{x} \Rightarrow_{\star} \mathrm{y}\right)$.

A negation function on $[0,1]$ is a unary operation $n:[0,1] \rightarrow[0,1]$ satisfying the following properties:

- $\mathrm{n}(0)=1$,

- $\mathrm{n}(1)=0$,

- for all $\mathrm{x}, \mathrm{y} \in[0,1], \mathrm{x} \leq \mathrm{y} \Rightarrow_{\star} \mathrm{n}(\mathrm{y}) \leq \mathrm{n}(\mathrm{x})$ (antimonotonicity).

We say that $\mathrm{n}$ is weak if, for all $\mathrm{x} \in[0,1], \mathrm{x} \leq \mathrm{n}(\mathrm{n}(\mathrm{x}))$; and it is said to be strong or involutive if, for all $\mathrm{x} \in[0,1], \mathrm{n}(\mathrm{n}(\mathrm{x}))=\mathrm{x}$. We can also associate to each leftcontinuous t-norm * a negation defined as follows: $\neg_{\star}(\mathrm{x})=\mathrm{x} \Rightarrow_{\star} 0$. This negation is always a weak negation function. If the t-norm * is continuous, $\neg_{*}$ is involutive if and only if $*$ is the Lukasiewicz t-norm.

An example of a prominent left-continuous t-norm that is not continuous is the Nilpotent Minimum (NM). Table 1 shows the NM t-norm and the main continuous t-norms (Minimum, Product and Lukasiewicz) with their residua and the corresponding associated negations. The three main continuous t-norms are the basic ones since any continuous t-norm can be expressed as an ordinal sum of copies of them [51,44]. In the following proposition we summarize some basic properties of left-continuous t-norms and their residua.

Proposition 1 . For every $\mathrm{x}, \mathrm{y} \in[0,1]$, the following conditions hold:
a) $x * y \leq x$ and $x * y \leq y$,
(Integrality condition)
b) $x \Rightarrow_{\star} y=1$ if and only if $x \leq y$,
c) $1 \Rightarrow_{\star} \mathrm{x}=\mathrm{x}$,
d) $\max \{x, y\}=\min \left\{\left(x \Rightarrow_{\star} y\right) \Rightarrow_{\star} y,\left(y \Rightarrow_{\star} x\right) \Rightarrow_{\star} x\right\}$ 


\begin{tabular}{|c|c|c|c|c|}
\hline * & NM & Minimum (Gödel) & Product & Łukasiewicz \\
\hline$x * y$ & $\begin{array}{ll}0, & \text { if } y \leq 1-x \\
\min \{x, y\}, & \text { otherwise }\end{array}$ & $\min \{x, y\}$ & $x \cdot y$ & $\max \{0, x+y-1\}$ \\
\hline $\mathrm{x} \rightarrow \star \mathrm{y}$ & $\begin{array}{ll}1, & \text { if } x \leq y \\
\max \{1-x, y\}, & \text { otherwise }\end{array}$ & $\begin{array}{l}1, \quad \text { if } x \leq y \\
y, \quad \text { otherwise }\end{array}$ & $\begin{array}{ll}1, & \text { if } x \leq y \\
y / x, & \text { otherwise }\end{array}$ & $\min \{1,1-x+y\}$ \\
\hline$\neg$ * & $1-x$ & $\begin{array}{l}1, \quad \text { if } x=0 \\
0, \quad \text { otherwise }\end{array}$ & $\begin{array}{l}1, \quad \text { if } x=0 \\
0, \quad \text { otherwise }\end{array}$ & $1-x$ \\
\hline
\end{tabular}

Table 1: NM and the three main continuous t-norms.

\begin{tabular}{|c|c|c|c|c|}
\hline$\oplus$ & NM & Maximum & Probabilistic sum & Łukasiewicz \\
\hline$x \oplus y$ & $\begin{array}{ll}1, & \text { if } 1 \leq x+y \\
\max \{x, y\}, & \text { otherwise }\end{array}$ & $\max \{\mathrm{x}, \mathrm{y})$ & $(x+y)-(x \cdot y)$ & $\min \{1, x+y\}$ \\
\hline
\end{tabular}

Table 2: Dual t-conorms with respect to the involutive negation $\mathrm{N}(\mathrm{x})=1-\mathrm{x}$.

A triangular conorm (or t-conorm) is a binary operation defined on $[0,1]$ that is associative, commutative, non decreasing in both arguments, and having 0 as unit element. We say that a t-norm $*$ and a t-conorm $\oplus$ are dual with respect to a negation $\mathrm{n}$ if, for every $\mathrm{x}, \mathrm{y} \in[0,1]$, the De Morgan laws hold:

$$
\mathrm{n}(\mathrm{x} * \mathrm{y})=\mathrm{n}(\mathrm{x}) \oplus \mathrm{n}(\mathrm{y}), \quad \mathrm{n}(\mathrm{x} \oplus \mathrm{y})=\mathrm{n}(\mathrm{x}) * \mathrm{n}(\mathrm{y}) .
$$

In Table 2 we show the t-conorms dual (with respect to the standard involutive negation $\mathrm{N}(\mathrm{x}):=1-\mathrm{x})$ to $\mathrm{NM}$ and the three main continuous t-norms.

The notion of t-norm can be extended to bounded finite chains with 0 and 1 as first and last element respectively (see $[48,49]$ ). We will call this kind of operations finite t-norms. They fulfill the same properties as t-norms and since they are of finite range all of them have a residuum. A finite t-norm satisfying the divisibility condition is called a divisible finite t-norm. In [23, Corollary 3.7] it is shown that finite BL-chains are also ordinal sums of finite Lukasiewicz and minimum, and their finite ordinal sums. 


\subsection{The predicate fuzzy logics MTL $\forall$ and $M T L \sim \forall$}

In the next we recall the axiomatization of the logic MTL. This logic, introduced in [31] by Esteva and Godo, was proved in [40] to be the logic of all the ordered algebraic structures defined by left-continuous t-norms and their residua over the unit real interval $[0,1]$.

The primitive connectives are strong conjunction $\&$, implication $\rightarrow$, weak conjunction $\wedge$, and the constant $\overline{0}$. Let $\phi, \psi, \chi$ be propositional formulas (schemata) in the language defined by connectives in $\{\&, \rightarrow, \wedge, \overline{0}\}$. The propositional logic MTL is defined by the following axioms and rule: ${ }^{1}$

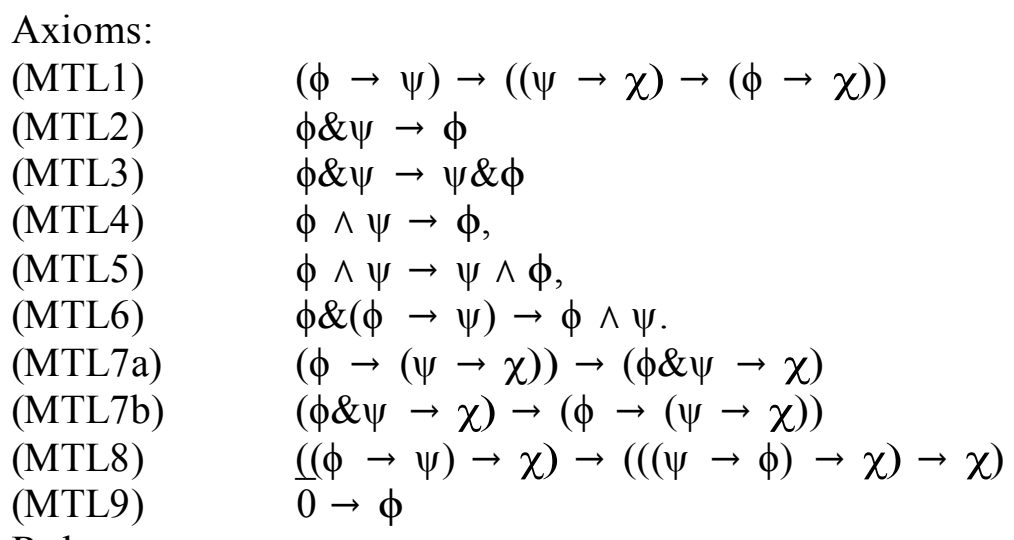

Rule:

Modus ponens: $\phi, \phi \rightarrow \psi \psi^{`} \psi$

Further connectives are defined as follows:

$$
\begin{gathered}
\phi \leftrightarrow \psi:=(\phi \rightarrow \psi) \&(\psi \rightarrow \phi), \\
\phi \vee \psi:=((\phi \rightarrow \psi) \rightarrow \psi) \wedge((\psi \overrightarrow{\bar{T}} \phi) \rightarrow \phi), \\
\neg \phi:=\phi \rightarrow 0, \quad 1:=\neg 0
\end{gathered}
$$

By adding to the axiomatization of MTL the axiom $\phi \wedge \psi \rightarrow \phi \&(\phi \rightarrow \psi)$ we obtain the logic BL, studied in [35] and proved in [23] to be the logic of all the ordered algebraic structures defined by continuous t-norms and their residua over the unit real interval $[0,1]$.

\footnotetext{
${ }^{1}$ In order to economize parenthesis in formulas, we will consider $\rightarrow$ the least binding connective.
} 
An MTL-algebra [31] is a prelinear commutative integral bounded residuated lattice, that is, an algebra

$$
\mathrm{A}=\mathrm{hA}, \vee, \wedge, *, \Rightarrow_{\star}, 0,1 \mathbf{i}
$$

with four binary operations and two distinguished elements, satisfying:

1. $h A, \vee, \wedge, 0,1 \mathbf{i}$ is a bounded lattice with minimum element 0 , and maximum element 1 .

2. $h A, *, 1 \mathbf{i}$ is a commutative monoid with unit 1 .

3. The operation $*$ is residuated and the operation $\Rightarrow_{*}$ is its residuum, i.e.,

$$
\text { for every } x, y, z \in A, x * y \leq z \text { if and only if } y \leq x \Rightarrow_{\star} z \text {, }
$$

where $\leq$ is the order associated to the lattice reduct.

4. For every $\mathrm{x}, \mathrm{y} \in \mathrm{A},\left(\mathrm{x} \Rightarrow_{\star} \mathrm{y}\right) \vee\left(\mathrm{y} \Rightarrow_{\star} \mathrm{x}\right)=1$. (Prelinearity)

A negation operator is defined in any MTL-algebra by $\neg \mathrm{x}:=\mathrm{x} \Rightarrow_{*} 0$. An MTL-chain is a linearly ordered MTL-algebra. When a MTL-algebra (chain) A satisfies the equation $\mathrm{x} *\left(\mathrm{x} \Rightarrow_{*} \mathrm{y}\right)=\mathrm{x} \wedge \mathrm{y}$, we say that $\mathrm{A}$ is a BL-algebra (chain). Given a left-continuous t-norm *, the algebraic structure

$$
[0,1]_{*}=h[0,1], \max , \min , * \Rightarrow_{*}, 0,1 \mathbf{i},
$$

where

- max and min are the binary operators giving the maximum an the minimum of two numbers, respectively;

- * is any left-continuous t-norm; and

- $\Rightarrow_{\star}$ is the residuum of $*$.

is called the standard chain relative to the t-norm *. It can be seen that an MTLchain is a BL-chain if and only if the t-norm is continuous [15, Corollary 1]. Since all chains with n elements are order-isomorphic, we can take as support of any finite MTL-chain of $n$ elements the set:

$$
\mathrm{C}_{\mathrm{n}}=\left\{0, \frac{1}{\mathrm{n}-1}, \frac{2}{\mathrm{n}-1}, \ldots, \frac{\mathrm{n}-2}{\mathrm{n}-1}, 1\right\} .
$$

Given a finite $t$-norm $*$ over $C_{n}$, the MTL-chain 


$$
\mathrm{C}_{\mathrm{n}}^{*}=h \mathrm{C}_{\mathrm{n}}, \max , \min , *, \Rightarrow_{\star}, 0,1 \mathbf{i}
$$

is called the standard chain relative to the finite $\mathrm{t}$-norm $*$. The canonical n-chains corresponding to the finite t-norms of NM, Łukasiewicz and Minimum (Gödel) are denoted by $\mathrm{NM}_{\mathrm{n}}, \mathrm{E}_{\mathrm{n}}$, and $\mathrm{G}_{\mathrm{n}}$, respectively. It is easy to see that a structure $\mathrm{C}_{\mathrm{n}}{ }_{\mathrm{n}}$ is a BL-chain if and only if the finite t-norm is divisible.

Now we state without proof some theorems of MTL that we will use later on:

Proposition 2. (Cf. [31]) The following formulas are theorems of MTL:

(1) $\phi \&(\psi \& \chi) \rightarrow(\phi \& \psi) \& \chi$

(2) $(\phi \& \psi) \& \chi \rightarrow \phi \&(\psi \& \chi)$,

(3) $\left(\phi_{1} \rightarrow \psi_{1}\right) \&\left(\phi_{2} \rightarrow \psi_{2}\right) \rightarrow\left(\left(\phi_{1} \& \phi_{2}\right) \rightarrow\left(\psi_{1} \& \psi_{2}\right)\right)$,

(4) $(\phi \leftrightarrow \psi) \rightarrow((\phi \rightarrow \chi) \leftrightarrow(\psi \rightarrow \chi))$,

(5) $\quad(\phi \leftrightarrow \psi) \rightarrow((\chi \rightarrow \phi) \leftrightarrow(\chi \rightarrow \psi))$,

(6) $\quad(\phi \leftrightarrow \psi) \&(\psi \leftrightarrow \chi) \rightarrow(\phi \leftrightarrow \chi)$,

(7) $(\phi \rightarrow \psi) \wedge(\phi \rightarrow \chi) \rightarrow(\phi \rightarrow \psi \wedge \chi)$,

(8) $\phi \& \psi \rightarrow \phi \wedge \psi$,

(9) $\phi \wedge \psi \rightarrow \psi \wedge \phi$,

(10) $\phi \wedge(\psi \wedge \chi) \rightarrow(\phi \wedge \psi) \wedge \chi$

(11) $(\phi \wedge \psi) \wedge \chi \rightarrow \phi \wedge(\psi \wedge \chi)$,

(12) $(\phi \rightarrow \psi) \rightarrow(\phi \wedge \chi \rightarrow \psi)$,

(13) $(\phi \rightarrow(\psi \rightarrow \chi)) \rightarrow(\psi \rightarrow(\phi \rightarrow \chi))$,

(14) $(\psi \rightarrow \chi) \rightarrow((\phi \rightarrow \psi) \rightarrow(\phi \rightarrow \chi))$,

(15) $(\phi \leftrightarrow \psi) \leftrightarrow(\phi \rightarrow \psi) \wedge(\psi \rightarrow \phi)$,

(16) $\left(\phi_{1} \rightarrow \psi_{1}\right) \wedge\left(\phi_{1} \rightarrow \psi_{1}\right) \rightarrow\left(\phi_{1} \wedge \phi_{2} \rightarrow \psi_{1} \wedge \psi_{2}\right)$.

We can extend the logic MTL with a involutive negation [30, Section 4.2]. We will denote this logic by MTL $\sim$ and it is obtained by adding to any axiomatization of MTL the following additional axiom and rule: ${ }^{2}$

$$
\begin{array}{ll}
(\sim) & \phi \leftrightarrow \sim \sim \phi \\
(\mathrm{OR}) & \text { from }(\phi \rightarrow \psi) \vee \chi \text { derive }(\sim \psi \rightarrow \sim \phi) \vee \chi
\end{array}
$$

an $\mathrm{MTL}^{\sim}$-chain is an algebraic structure

$$
\mathrm{A}=\mathrm{hA}, \vee, \wedge, *, \Rightarrow_{*}, \sim, 0,1 \mathbf{i}
$$

\footnotetext{
${ }^{2}$ Recall that the connective $\vee$ is defined as $\phi \vee \psi:=((\phi \rightarrow \psi) \rightarrow \psi) \wedge((\psi \rightarrow \phi) \rightarrow \phi)$.
} 
such that $h A, \vee, \wedge, *, \Rightarrow_{*}, 0,1 \mathbf{i}$ is a $\mathrm{MTL}^{\sim}$-chain and the following properties hold for every $\mathrm{x}, \mathrm{y}, \mathrm{z} \in \mathrm{A}$ :

$$
\begin{aligned}
& -\sim \sim \mathrm{x}=\mathrm{x}, \\
& \text { - } \quad \text { if }\left(\mathrm{x} \Rightarrow_{*} \mathrm{y}\right) \vee \mathrm{z}=1, \text { then }\left(\sim \mathrm{y} \Rightarrow_{*} \sim \mathrm{x}\right) \vee \mathrm{z}=1 .
\end{aligned}
$$

Given a t-norm *, the chain $[0,1]_{*}$ expanded with the standard involutive negation $\mathrm{N}(\mathrm{x})=1-\mathrm{x}$ is called the canonical involutive chain relative to $*$. In the same way, given a finite $\mathrm{t}$-norm $*$, the chain $\mathrm{C}_{\mathrm{n}}^{*}$ expanded with the standard involutive negation is called the canonical finite involutive chain relative to *.

The first-order versions of MTL and MTL $\sim$, denoted respectively by MTL $\forall$ and $\mathrm{MTL} \sim \forall$, are obtained by adding to their axiomatizations the following axioms and rule (where now $\phi, \psi, \chi$ must be read as predicate formulas):

Axioms:

$$
\begin{aligned}
& (\forall \mathrm{x}) \phi(\mathrm{x}) \rightarrow \phi(\mathrm{v}) \quad(\mathrm{v} \text { substitutable for } \mathrm{x} \text { in } \phi) \\
& (\forall \mathrm{x})(\phi(\mathrm{x}) \rightarrow \psi(\mathrm{x})) \rightarrow(\phi(\mathrm{x}) \rightarrow(\forall \mathrm{x}) \psi(\mathrm{x}))(\mathrm{x} \text { not free in } \phi) \\
& (\forall \mathrm{x})(\phi(\mathrm{x}) \vee \psi(\mathrm{x})) \rightarrow(\phi(\mathrm{x}) \vee(\forall \mathrm{x}) \psi(\mathrm{x})) \quad(\mathrm{x} \text { not free in } \phi) \\
& \phi(\mathrm{v}) \rightarrow(\exists \mathrm{x}) \phi(\mathrm{x}) \quad \text { (v substitutable for } \mathrm{x} \text { in } \phi) \\
& (\forall \mathrm{x})(\phi(\mathrm{x}) \rightarrow \psi(\mathrm{x})) \rightarrow((\exists \mathrm{x}) \phi(\mathrm{x}) \rightarrow \psi(\mathrm{x}))(\mathrm{x} \text { not free in } \psi)
\end{aligned}
$$

Rule:

Generalization: $\quad \phi^{-}(\forall \mathrm{x}) \phi(\mathrm{x})$

In the next proposition we recall two theorems of MTL $\forall$ that we will use later on:

Proposition 3. (Cf. [31]) The following formulas are theorems of MTL $\forall$ :

(1) $(\forall x)(\phi \rightarrow \psi) \rightarrow((\forall x) \phi \rightarrow(\forall x) \psi)$,

(2) $(\forall \mathrm{x})(\phi \rightarrow \psi) \rightarrow((\exists \mathrm{x}) \phi \rightarrow(\exists \mathrm{x}) \psi)$.

Definition 1 (First-order semantics). Let hP, Fi a first-order signature (predicate symbols and functional symbols). Given a finite or infinite involutive canonical $\mathrm{MTL}^{\sim}$-chain $\mathrm{T}_{*}$, a $\mathrm{T}_{*}$-structure for the signature $\mathrm{hP}, \mathrm{Fi}$ is a tuple

$$
\mathrm{M}=h \mathrm{M},\left\{\mathrm{P}^{\mathrm{M}}: \mathrm{P} \in \mathrm{P}\right\},\left\{\mathrm{f}^{\mathrm{M}}: \mathrm{f} \in \mathrm{F}\right\} \mathbf{i}
$$

where 
1) $\mathrm{M}$ is a non-empty set (the universe of the structure);

2) for each $k$-ary $P \in P, \quad \begin{array}{ll}P^{M}: M^{k}-\rightarrow[0,1], & \text { ifk } \geq 1, \\ P^{M} \in[0,1], & \text { ifk }=0 ;\end{array}$

$\begin{array}{ll}\text { 3) for each k-ary } f \in F, & f^{M}: M^{k} \rightarrow M, \\ f^{M} \in M, & \begin{array}{l}\text { ifk } \geq 1, \\ \text { if } k=0 .\end{array}\end{array}$

Given an assignation $v$ of the variables in $M$, the value of a term $t$ in $M$ is defined by:

$$
\mathrm{ktk}_{\mathrm{M}, \mathrm{v}}=\begin{array}{cl}
\square(\mathrm{x}), & \text { if } \mathrm{t}=\mathrm{x}, \\
\mathrm{a}^{\mathrm{M}} & \text { if } \mathrm{t} \text { is a constant } \mathrm{a}, \\
\mathrm{f}^{\mathrm{M}}\left(\mathrm{kt}_{1} \mathrm{k}_{\mathrm{M}, \mathrm{v}}, \ldots, \mathrm{kt}_{\mathrm{k}} \mathrm{k}_{\mathrm{M}, \mathrm{v}}\right), & \text { if } \mathrm{t}=\mathrm{f}\left(\mathrm{t}_{1}, \ldots, \mathrm{t}_{\mathrm{k}}\right) .
\end{array}
$$

Let $\mathrm{v}$ be an M-assignation such that $\mathrm{v}\left(\mathrm{x}_{1}\right)=\mathrm{b}_{1}, \ldots, \mathrm{v}\left(\mathrm{x}_{\mathrm{n}}\right)=\mathrm{b}_{\mathrm{n}}$. The truth value over the chain $\mathrm{T}_{*}$ of a formula for $\mathrm{v}$ is a value in $[0,1]$ inductively defined as follows:

$$
\begin{aligned}
& \mathrm{kP}\left(\mathrm{t}_{1}, \ldots, \mathrm{t}_{\mathrm{k}}\right) \mathrm{k}_{\mathrm{M}, \mathrm{v}}^{\mathrm{*}}=\mathrm{P}^{\mathrm{M}}\left(\mathrm{kt}_{1} \mathrm{k}_{\mathrm{M}, \mathrm{v}}, \ldots, \mathrm{kt}_{\mathrm{k}} \mathrm{k}_{\mathrm{M}, \mathrm{v}}\right) \\
& \mathrm{k} \alpha \vee \beta \mathrm{k}_{\mathrm{M}, \mathrm{v}}^{*}=\max \left(\mathrm{k} \alpha \mathrm{K}_{\mathrm{M}, \mathrm{v}}^{*}, \mathrm{k} \beta \mathrm{k}_{\mathrm{M}, \mathrm{v}}^{*}\right) \\
& \mathrm{k} \alpha \wedge \beta \mathrm{k}_{\mathrm{M}, \mathrm{v}}^{*}=\min \left(\mathrm{k} \alpha \mathrm{k}_{\mathrm{M}, \mathrm{v}}^{*}, \mathrm{k} \beta \mathrm{k}_{\mathrm{M}, \mathrm{v}}^{*}\right) \\
& \mathrm{k} \alpha \& \beta \mathrm{k}_{\mathrm{M}, \mathrm{v}}^{*}=\mathrm{k}_{\alpha} \mathrm{k}_{\mathrm{M}, \mathrm{v}}^{*} * \mathrm{k} \beta \mathrm{k}^{*} \\
& \mathrm{k} \alpha \rightarrow \beta \mathrm{k}_{\mathrm{M}, \mathrm{v}}^{*}=k \alpha \mathrm{k}_{\mathrm{M}, \mathrm{v}}^{*} \Rightarrow_{*} \mathrm{k}^{\mathrm{M}, \mathrm{v}} \mathrm{k}_{\mathrm{M}, \mathrm{v}}^{*} \\
& \mathrm{k} \sim \alpha \mathrm{k}_{\mathrm{M}, \mathrm{v}}^{*}=1-\mathrm{k}^{*} \mathrm{k}^{*} \\
& \mathrm{k}(\forall \mathrm{x}) \alpha\left(\mathrm{x}, \mathrm{x}_{1}, \ldots, \mathrm{x}_{\mathrm{n}}\right) \mathrm{k}_{\mathrm{M}, \mathrm{v}}^{*}=\inf \left\{\mathrm{k} \alpha\left(\mathrm{a}, \mathrm{b}_{1}, \ldots, \mathrm{b}_{\mathrm{n}}\right){ }^{*}: \mathrm{a} \in \mathrm{M}\right\} \\
& \mathrm{k}(\exists \mathrm{x}) \alpha\left(\mathrm{x}, \mathrm{x}_{1}, \ldots, \mathrm{x}_{\mathrm{n}}\right) \mathrm{k}_{\mathrm{M}, \mathrm{v}}^{*}=\sup \left\{\mathrm{k} \alpha\left(\mathrm{a}, \mathrm{b}_{1}, \ldots, \mathrm{b}_{\mathrm{n}}\right) \mathrm{k}_{\mathrm{M}}^{*}: \mathrm{a} \in \mathrm{M}\right\}
\end{aligned}
$$

A formula $\phi$ is valid in an $\mathrm{T}_{*}$-structure $\mathrm{M}$ (denoted as $h \mathrm{~T}_{*}, \mathrm{Mi} \vDash \phi$ ) if, for every assignation $\mathrm{v}, \mathrm{k} \phi \mathrm{k}_{\mathrm{M}, \mathrm{v}}^{*}=1$. A theory is a set of first-order formulas. A $\mathrm{T}_{*}$-structure $\mathrm{M}$ is a $\mathrm{T}{ }_{*}$-model of a theory $\Gamma$ if $h \mathrm{~T}_{*}, \mathrm{Mi} \models \phi$ for each $\phi \in \Gamma$.

3. The classical description logic ALC

In this section we describe the basic DL language ALC (Attributive Language with Complementation) [6], its semantics, and its knowledge bases. The vocab- 


\begin{tabular}{l|cl|}
\hline NAME & SYNTAX & SEMANTICS \\
Top & $>$ & $\Delta^{\mathbf{I}}$ \\
Bottom & $\perp$ & $\emptyset$ \\
Intersection & $\mathrm{C} \mathrm{u} \mathrm{D}$ & $\mathrm{C}^{\mathbf{I}} \cap \mathrm{D}^{\mathbf{I}}$ \\
Union & $\mathrm{C} \mathbf{t} \mathrm{D}$ & $\mathrm{C}^{\mathbf{I}} \cup \mathrm{D}^{\mathbf{I}}$ \\
Complementation & $\neg \mathrm{C}$ & $\Delta^{\mathbf{I}} \backslash \mathrm{C}^{\mathbf{I}}$ \\
Value restriction & $\forall R . C$ & $\left\{\mathrm{a} \in \Delta^{\mathbf{I}}:\left\{\mathrm{b} \in \Delta^{\mathbf{I}}:\right.\right.$ ha, bi $\left.\left.\in \mathrm{R}^{\mathbf{I}}\right\} \subseteq \mathrm{C}^{\mathbf{I}}\right\}$ \\
Existential restriction & $\exists R . C$ & $\left\{\mathrm{a} \in \Delta^{\mathbf{I}}:\left\{\mathrm{b} \in \Delta^{\mathbf{I}}:\right.\right.$ ha, $\left.\left.\mathrm{b} \mathbf{i} \in \mathrm{R}^{\mathbf{I}}\right\} \cap \mathrm{C}^{\mathbf{I}}=\varnothing\right\}$ \\
\hline
\end{tabular}

Table 3: Concept constructors for ALC.

ulary of ALC consists of individuals, which denote domain objects, concepts, which denote sets of objects, and roles, which denote binary relations among objects. From atomic concepts and roles and by means of constructors, DL systems allow us to build complex descriptions of both concepts and roles. These complex descriptions are used to describe a domain through a knowledge base (KB) containing the definitions of relevant domain concepts or some hierarchical relationships among them (Terminological Box), and a specification of properties of the domain instances (Assertional Box). One of the main issues of DLs is the fact that the expressions contained in the KB can be identified with formulas in firstorder logic or an extension of it; therefore we can use reasoning to obtain explicit knowledge from the knowledge in the $\mathrm{KB}$.

Next we recall the definition of the basic language ALC. We will use the letters $\mathrm{A}$ for atomic concepts, $\mathrm{R}$ for atomic roles and both $\mathrm{C}$ and $\mathrm{D}$ for descriptions of concepts. Concept descriptions in classic ALC can be built using the following syntactical rules

$$
\text { C, D } \quad \mathrm{A}|>| \perp \mid \mathrm{C} \text { u D } \mid \mathrm{C} \text { t D }|\neg \mathrm{C}| \forall \text { R.C } \mid \exists R . C
$$

In order to define a formal semantics for the description formulas we consider interpretations. An interpretation $\mathbf{I}$ is a pair $h \Delta^{\mathbf{I}},(.)^{\mathbf{I}} \mathbf{i}$, where $\Delta^{\mathbf{I}}$ is a non-empty set (the interpretation domain), and (.) ${ }^{\mathbf{I}}$ is a map, which assigns to every atomic concept $A$ a set $A^{\mathbf{I}} \subseteq \Delta^{\mathbf{I}}$ and to every atomic role $\mathrm{R}$ a binary relation $\mathrm{R}^{\mathbf{I}} \subseteq$ $\Delta^{\mathbf{I}} \times \Delta^{\mathbf{I}}$. Table 3 shows the name, syntax and semantics for each constructor of the language ALC.

Commonly, a knowledge base in classical DLs is formed by a Terminological Box (TBox) and an Assertional Box (ABox):

- In its more general form a TBox is a finite set of (general) concept inclusion 


$\begin{array}{lll}\text { Female u Male } & \mathbf{v} \\ \text { Man } & \equiv & \text { Human u Male } \\ \text { Woman } & \equiv & \text { Human u Female } \\ \text { Mother } & \equiv & \text { Woman u } \text { GhasChild.Human } \\ \text { Father } & \equiv & \text { Man u } \exists \text { hasChild.Human } \\ \text { Parent } & \equiv & \text { Father } \mathbf{t} \text { Mother }\end{array}$

Figure 1: Example of TBox in ALC.

axioms, which are expressions of the form $\mathrm{C} \vee \mathrm{D}$. An interpretation $\mathbf{I}$ satisfies the axiom $C \vee D$ if and only if $C^{\mathbf{I}} \subseteq D^{\mathbf{I}}$. In a TBox there are also equivalences, that is, expressions of the form $\mathrm{C} \equiv \mathrm{D}$ meaning that $\mathrm{C} \vee \mathrm{D}$ and $\mathrm{D} \vee \mathrm{C}$ are both contained in the TBox. Obviously, an interpretation $\mathbf{I}$ satisfies an equivalence $\mathrm{C} \equiv \mathrm{D}$ when $\mathrm{C}^{\mathbf{I}}=\mathrm{D}^{\mathbf{I}}$. An interpretation $\mathbf{I}$ which satisfies a TBox $\mathrm{T}$ is said to be a model of $\mathrm{T}$.

- An ABox for ALC is a finite set of formal expressions of the form C(a) (concept assertion axiom) and $\mathrm{R}(\mathrm{a}, \mathrm{b})$ (role assertion axiom). The semantics of an ABox is given by extending the interpretation $\mathbf{I}$ mapping each individual name a to an element $\mathbf{a}^{\mathbf{I}} \in \Delta^{\mathbf{I}}$. The interpretation $\mathbf{I}$ satisfies the axiom $\mathrm{C}(\mathrm{a})$ if and only if $\mathrm{a}^{\mathbf{I}} \in \mathrm{C}^{\mathbf{I}}$, and it satisfies $\mathrm{R}(\mathrm{a}, \mathrm{b})$ if and only if $\left(\mathrm{a}^{\mathbf{I}}, \mathrm{b}^{\mathbf{I}}\right) \in \mathrm{R}^{\mathbf{I}}$. An interpretation $\mathbf{I}$ which satisfies an assertion $\alpha$ is said to be a model of $\alpha$. We will say that $\mathbf{I}$ satisfies $\alpha$ with respect to a TBox $T$ if in addition to being a model of $\alpha$, it is a model of T .

As an example Fig.1 shows a possible TBox describing objects represented using only constructors from ALC. In this language Human, Female and Male are atomic concepts. Then, Human $u$ Male and Human $u$ Female are concepts describing Man and Woman respectively. If we have hasChild as an atomic role, we can consider the concept Human $u$ GhasChild.Man describing those humans having at least a son, or the concept Human $u \forall$ hasChild.Woman, which denotes those humans having only daughters. We can also define the concepts Father and Mother.

\section{The Fuzzy Description Logic IALCE}

The role played in classical DLs by the basic logic ALC is played in the fuzzy setting by the logic IALCE $[8,22]$. As in the classical case, we will use letters A 
for atomic concepts, $\mathrm{R}$ for atomic roles, and $\mathrm{C}$ and $\mathrm{D}$ for description of concepts. Concept descriptions in IALCE can be built using the following syntactical rules

$$
\mathrm{C}, \mathrm{D} \quad \mathrm{A}|\perp|>\mid \mathrm{C} \text { u D }|\mathrm{C} \mathbf{t} \mathrm{D}| \mathrm{C} \rightarrow \mathrm{D}|\sim \mathrm{C}| \neg \mathrm{C}|\forall \mathrm{R} . \mathrm{C}| \exists \mathrm{R} . \mathrm{C}
$$

We will consider only finite alphabets. Notice that so defined, the difference between IALCE and ALC is the presence in the former of two new constructors: the implication and a new negation $(\sim)$. In the classical interpretation, both languages are equivalent because implication is definable in terms of other constructors like for instance $\neg$ and $\mathbf{t}$, and the two negations are semantically the same.

The semantics for concept constructors of IALCE is based on the ordered algebraic structures defined on the unit real interval (or on the $n$ elements chain $\mathrm{C}_{\mathrm{n}}=\left\{0, \frac{1}{\mathrm{n}-1}, \ldots, \frac{\mathrm{n}-2}{\mathrm{n}-1}, 1\right\}$ ) by a left continuous t-norm (or a finite t-norm) * and its residuum $\Rightarrow_{*}$, the standard involutive negation function $\mathrm{N}(\mathrm{x})=1-\mathrm{x}$, and the $\mathrm{t}$-conorm $\oplus$ dual of the $\mathrm{t}$-norm with respect to $\mathrm{N}$. A fuzzy interpretation is a triple $\mathbf{I}=h \Delta^{\mathbf{I}},(.)^{\mathbf{I}}, * \mathbf{i}$, where $\Delta^{\mathbf{I}}$ is a crisp non-empty set but, in this case, the map $(.)^{\mathbf{I}}$ assigns to every atomic concept $A$, a function $A^{\mathbf{I}}: \Delta^{\mathbf{I}} \rightarrow[0,1]$, i.e., a fuzzy set on $\Delta^{\mathbf{I}}$; and it assigns to every atomic role $\mathrm{R}$, a function $\mathrm{R}^{\mathbf{I}}: \Delta^{\mathbf{I}} \times \Delta^{\mathbf{I}} \rightarrow[0,1]$, i.e., a fuzzy binary relation on $\Delta^{\mathbf{I}}$. Notice that this definition generalizes the classical notion of interpretation to the fuzzy setting. ${ }^{3}$ For IALCE, the map (.) ${ }^{\mathbf{I}}$ can be inductively extended to other concept constructors (cf. [34]) in the following way:

$$
\begin{aligned}
\perp^{\mathbf{I}}(\mathrm{a}) & =0 \\
>^{\mathbf{1}}(\mathrm{a}) & =1 \\
(\mathrm{C} \text { u D })^{\perp}(\mathrm{a}) & =\mathrm{C}^{\mathbf{1}}(\mathrm{a}) * \mathrm{D}^{\mathbf{1}}(\mathrm{a}) \\
(\mathrm{C} \text { t D })^{\mathbf{1}}(\mathrm{a}) & =1-\left[\left(1-\mathrm{C}^{\mathbf{1}}(\mathrm{a})\right) *\left(1-\mathrm{D}^{\mathbf{1}}(\mathrm{a})\right)\right] \\
(\mathrm{C} \rightarrow \mathrm{D})^{\mathbf{1}}(\mathrm{a}) & =\mathrm{C}^{\mathbf{1}}(\mathrm{a}) \Rightarrow_{*} \mathrm{D}^{\mathbf{1}}(\mathrm{a}) \\
(\sim \mathrm{C})^{\mathbf{1}}(\mathrm{a}) & =1-\mathrm{C}^{\mathbf{1}}(\mathrm{a}) \\
(\neg \mathrm{C})^{\mathbf{1}}(\mathrm{a}) & =\mathrm{C}^{\mathbf{1}}(\mathrm{a}) \Rightarrow_{*} 0 \\
(\forall \mathrm{R} . \mathrm{C})^{\mathbf{1}}(\mathrm{a}) & =\inf \left\{\mathrm{R}^{\mathbf{1}}(\mathrm{a}, \mathrm{b}) \Rightarrow_{\star} \mathrm{C}^{\mathbf{1}}(\mathrm{b}): \mathrm{b} \in \Delta^{\mathbf{1}}\right\} \\
(\exists R . C)^{\mathbf{1}}(\mathrm{a}) & =\sup \left\{\mathrm{R}^{\mathbf{1}}(\mathrm{a}, \mathrm{b}) * \mathrm{C}^{\mathbf{1}}(\mathrm{b}): \mathrm{b} \in \Delta^{\mathbf{1}}\right\}
\end{aligned}
$$

A fuzzy KB is composed of a fuzzy TBox and a fuzzy ABox. A fuzzy TBox is a finite set of graded concept inclusion axioms. A fuzzy ABox is a finite set of

\footnotetext{
${ }^{3} \mathrm{~A}$ crisp set $\mathrm{A}^{\mathbf{I}} \subseteq \Delta^{\mathbf{I}}$ (resp. a crisp binary relation $\left.\mathrm{R}^{\mathbf{I}} \subseteq \Delta^{\mathbf{I}} \times \Delta^{\mathbf{I}}\right)$ can be equivalently seen as the characteristic function $A^{\mathbf{I}}: \Delta^{\mathbf{I}} \rightarrow\{0,1\}$ (resp. $\mathrm{R}^{\mathbf{I}}: \Delta^{\mathbf{I}} \times \Delta^{\mathbf{I}} \rightarrow\{0,1\}$ ), associated to the set $\mathrm{A}^{\mathbf{I}}$ (resp. $\mathrm{R}^{\mathbf{I}}$ ) w.r.t. the universe $\Delta^{\mathbf{I}}\left(\right.$ resp. $\Delta^{\mathbf{I}} \times \Delta^{\mathbf{I}}$ ).
} 
graded concept assertion axioms and graded role assertion axioms. Let $\mathrm{C}, \mathrm{D}$ be concepts, $\mathrm{R}$ be an atomic role and $\mathrm{a}, \mathrm{b}$ be individual names. Let $\mathrm{T} \in\left\{\mathrm{C}_{\mathrm{n}},[0,1]\right\}$ and let $r \in T$. A graded concept inclusion axiom is an expression of the form:

$$
\text { hC } \vee \mathrm{D}, \mathrm{ri} \text {. }
$$

A graded concept assertion axiom is an expression of the form:

$$
\text { hC(a), ri. }
$$

A graded role assertion axiom is an expression of the form:

$$
h R(a, b), r i \text {. }
$$

We denote by $\models$ the satisfiability relation. Given a fuzzy interpretation $\mathbf{I}$, the semantics for these fuzzy axioms is the following:

$$
\begin{array}{lll}
\mathbf{I}=h C \vee \mathrm{V}, \mathbf{r i} & \text { iff } & \inf \left\{\mathrm{C}^{\mathbf{I}}(\mathrm{x}) \Rightarrow_{\star} \mathrm{D}^{\mathbf{I}}(\mathrm{x}): \mathrm{x} \in \Delta^{\mathbf{I}}\right\} \geq \mathbf{r}, \\
\mathbf{I}=h \mathrm{C}(\mathrm{a}), \mathbf{r i} & \text { iff } & \mathrm{C}^{\mathbf{I}}\left(\mathrm{a}^{\mathbf{I}}\right) \geq \mathbf{r}, \\
\mathbf{I}=h \mathbf{R}(\mathrm{a}, \boldsymbol{b}), \mathbf{r i} & \text { iff } & \mathrm{R}^{\mathbf{I}}\left(\mathrm{a}^{\mathbf{I}}, \mathrm{b}^{\mathbf{I}}\right) \geq \mathbf{r} .
\end{array}
$$

For instance, to express that a person $p$ has most of his hair white, we can use a formula that says that $\mathrm{p}$ has white hair up to some degree:

$$
\text { hHair_White(p), } 0.7 \mathbf{i}
$$

\section{Similarities in Fuzzy Description Logics}

In this section we recall some basic definitions and properties of the notion of similarity in Predicate Fuzzy Logics [35] and then we propose the introduction of a Similarity Box (SBox) in FDLs and show under which conditions an interpretation satisfies the axioms contained in the SBox. In Mathematical Fuzzy Logic such notion is formalized by means of equivalence and congruence relations. However, in other domains such as psychology, for instance Tversky's stimuli judged similarity [62], its formalization enjoys different properties and two objects may be similar in the context of a notion of similarity that for instance it does not suppose transitivity as a necessary condition. In [18] (see also [17]) Bouchon-Meunier et al. have developed a very broad notion of comparison compatible with the notions proposed by Tversky in [62] (see Section 8). Our aim is to introduce in the language roles interpreted as similarities (possibly with different properties, depending of the domain) and to endow DL languages with the appropriate tools to reason with them, the techniques to obtain that will be developed in 
future work. In the current paper we restrict ourselves to the following notion of similarity.

Definition 2. Given a t-norm $*, a *$-similarity relation (or a fuzzy $*$-equivalence) defined on a universe $M$ is a function

$$
\begin{gathered}
\mathrm{s}: \mathrm{M} \times \mathrm{M} \rightarrow[0,1] \\
\mathrm{hx}, \mathrm{yi} 7 \rightarrow \mathrm{s}(\mathrm{x}, \\
\mathrm{y})
\end{gathered}
$$

such that, for every $a, b, c \in M$, the following hold:

1. $\mathrm{s}(\mathrm{a}, \mathrm{a})=1$,

(Reflexivity)

2. $s(a, b)=s(b, a)$

3. $s(a, b) * s(b, c) \leq s(a, c)$.

(Transitivity)

Definition 3. We say that an $n$-ary fuzzy relation $r$ is extensional (or congruent) with respect to $\mathrm{a} *$-similarity $\mathrm{s}$ on $\mathrm{M}$ when, for every $\mathrm{u}_{1}, \ldots, \mathrm{u}_{\mathrm{n}}, \mathrm{v}_{1}, \ldots, \mathrm{v}_{\mathrm{n}} \in \mathrm{M}$,

$$
\mathrm{s}\left(\mathrm{u}_{1}, \mathrm{v}_{1}\right) * \cdots * \mathrm{~s}\left(\mathrm{u}_{\mathrm{n}}, \mathrm{v}_{\mathrm{n}}\right) * \mathrm{r}\left(\mathrm{u}_{1}, \ldots, \mathrm{u}_{\mathrm{n}}\right) \leq \mathrm{r}\left(\mathrm{v}_{1}, \ldots, \mathrm{v}_{\mathrm{n}}\right) .
$$

We say that a k-ary funcion $\mathrm{F}$ is extensional (or congruent) with respect to a *-similarity $\mathrm{s}$ on $\mathrm{M}$ when, for every $\mathrm{u}_{1}, \ldots, \mathrm{u}_{\mathrm{n}}, \mathrm{v}_{1}, \ldots, \mathrm{v}_{\mathrm{n}} \in \mathrm{M}$,

$$
\mathrm{s}\left(\mathrm{u}_{1}, \mathrm{v}_{1}\right) * \cdots * \mathrm{~s}\left(\mathrm{u}_{\mathrm{n}}, \mathrm{v}_{\mathrm{n}}\right) \leq \mathrm{s}\left(\mathrm{F}\left(\mathrm{u}_{1}, \ldots, \mathrm{u}_{\mathrm{n}}\right), \mathrm{F}\left(\mathrm{v}_{1}, \ldots, \mathrm{v}_{\mathrm{n}}\right)\right) .
$$

Hájek in [35] studies similarities and congruences in the predicate fuzzy logic $\mathrm{BL} \forall$ and proposes the following similarity axioms:

(S1) $(\forall \mathrm{x}) \mathrm{x} \approx \mathrm{x}$

(S2) $(\forall \mathrm{x}, \mathrm{y})(\mathrm{x} \approx \mathrm{y} \rightarrow \mathrm{y} \approx \mathrm{x})$

(Reflexivity)

(S3) $(\forall \mathrm{x}, \mathrm{y}, \mathrm{z})(\mathrm{x} \approx \mathrm{y} \& \mathrm{y} \approx \mathrm{z} \rightarrow \mathrm{x} \approx \mathrm{z}) \quad$ (Transitivity)

and a congruence axiom (or extensionality axiom) for every $n$-ary predicate $\mathrm{P}$ and every $\mathrm{k}$-ary functional $\mathrm{f}$ in the language:

$$
\begin{aligned}
& (\text { Cong })_{\mathrm{P}} \quad\left(\forall \mathrm{x}_{1}, \ldots, \mathrm{x}_{\mathrm{n}}, \mathrm{y}_{1}, \ldots, \mathrm{y}_{\mathrm{n}}\right)\left(\mathrm{x}_{1} \approx \mathrm{y}_{1} \& \cdots \& \mathrm{x}_{\mathrm{n}} \approx \mathrm{y}_{\mathrm{n}} \rightarrow\right. \\
& \left.\rightarrow\left(\mathrm{P}_{1}, \ldots, \mathrm{x}_{\mathrm{n}} \leftrightarrow \mathrm{P}_{1}, \ldots, \mathrm{y}_{\mathrm{n}}\right)\right) . \\
& (\text { Cong })_{\mathrm{f}} \quad\left(\forall \mathrm{x}_{1}, \ldots, \mathrm{x}_{\mathrm{k}}, \mathrm{y}_{1}, \ldots, \mathrm{y}_{\mathrm{k}}\right)\left(\mathrm{x}_{1} \approx \mathrm{y}_{1} \& \cdots \& \mathrm{x}_{\mathrm{k}} \approx \mathrm{y}_{\mathrm{k}} \rightarrow\right. \\
& \left.\rightarrow\left(\mathrm{fx}_{1}, \ldots, \mathrm{x}_{\mathrm{k}} \approx \mathrm{fy}_{1}, \ldots, \mathrm{y}_{\mathrm{k}}\right)\right) \text {. }
\end{aligned}
$$

The following result is proved by Hájek (see [35, Section 5.6]) in the context of the logic BL $\forall$. The generalization to the context of MTL $\sim \forall$ is straightforward.

Lemma 1 . Let $\mathrm{T}_{\star}$ be a finite or infinite involutive canonical $\mathrm{MTL}^{\sim}{ }^{\sim}$-chain. 
a) If $h \mathrm{M}$, si is a $\mathrm{T}_{*}$-model of the axioms of similarity, then the fuzzy relation $\mathbf{s}$ is a $*$-similarity.

b) Let $\mathrm{M}=h \mathrm{M}$, s, ri be a $\mathrm{T}_{*}$-interpretation of the binary predicate $\approx$ and the $\mathrm{n}$-ary predicate $\mathrm{P}$ which is a $\mathrm{T}_{*}$-model of the axioms of similarity. Then, $\mathrm{M}$ is a $\mathrm{T}_{*}$-model of $(\mathrm{Cong})_{\mathrm{P}}$ if and only if $\mathrm{r}$ is extensional with respect to S.

c) Let $\mathrm{M}=\mathrm{hM}, \mathrm{s}, \mathrm{F}$ i be a $\mathrm{T}_{*}$-interpretation of the binary predicate $\approx$ and the $\mathrm{k}$-ary functional $\mathbf{f}$ which is a $\mathrm{T}{ }_{*}$-model of the axioms of similarity. Then, $\mathrm{M}$ is a $\mathrm{T}_{*}$-model of $(\mathrm{Cong})_{\mathrm{f}}$ if and only if $\mathrm{F}$ is extensional with respect to s.

\subsection{Introducing the Similarity Box}

We propose to extend the knowledge bases of IALCE F (D) by adding a Similarity Box. To do so we must extend the language by allowing abstract roles (only in the SBox, not in the other boxes). In the SBox we want to express that a role is reflexive, symetric, transitive or that it is a congruence.

An SBox consists of a finite set of axioms of one of these types, where $\mathrm{S}$ is an abstract role:

- reflexive role axioms $\operatorname{ref}(\mathrm{S})$,

- symmetric role axioms sym(S),

- transitive role axioms trans $(\mathrm{S})$,

- congruence role axioms cong(S).

Given an interpretation $\mathbf{I}=h \Delta^{\mathbf{I}},(\cdot)^{\mathbf{I}}, * i$, the semantics for these axioms is the following one:

- $\mathbf{I} \models \operatorname{ref}(\mathrm{S})$ if and only if, for every a $\in \Delta^{\mathbf{I}}, \mathrm{S}^{\mathbf{I}}(\mathrm{a}, \mathrm{a})=1$,

- $\mathbf{I} \models \operatorname{sym}(S)$ if and only if, for every $a, b \in \Delta^{\mathbf{I}}, S^{\mathbf{I}}(a, b)=S^{\mathbf{I}}(b, a)$,

- $\mathbf{I}=\operatorname{trans}(\mathrm{S})$ if and only if, for every a, b, c $\in \Delta^{\mathbf{I}}$,

$$
\mathrm{S}^{\mathbf{I}}(\mathrm{a}, \mathrm{c}) * \mathrm{~S}^{\mathbf{I}}(\mathrm{c}, \mathrm{b}) \leq \mathrm{S}^{\mathbf{I}}(\mathrm{a}, \mathrm{b}) .
$$

- $\mathbf{I} \models \operatorname{cong}(\mathrm{S})$ if and only if, for every atomic concept $\mathrm{A}$, atomic role $\mathrm{R}$, and $\mathrm{u}, \mathrm{v}, \mathrm{u}_{1}, \mathrm{u}_{2}, \mathrm{v}_{1}, \mathrm{v}_{2} \in \Delta^{\mathbf{I}}$, 


\begin{tabular}{|l|l|}
\hline $\operatorname{ref}(\mathrm{S})$ & $\mathrm{h}>\mathbf{v} \exists \mathrm{S}$. Self, $1 \mathbf{i}$ \\
$\operatorname{sym}(\mathrm{S})$ & $h S^{-} \mathbf{v}, 1 \mathbf{i}$ \\
$\operatorname{trans}(\mathrm{S})$ & $h \mathrm{~S} \cdot \mathrm{S} \mathbf{v} \mathrm{S}, 1 \mathbf{i}$ \\
\hline
\end{tabular}

Table 4: The axioms of reflexivity, symmetry and transitivity expressed by means of inclusion axioms

1) $S^{\mathbf{I}}(u, v) * A^{\mathbf{I}}(u) \leq A^{\mathbf{I}}(v)$,

2) $\mathrm{S}^{\mathbf{I}}\left(\mathrm{u}_{1}, \mathrm{v}_{1}\right) * \mathrm{~S}^{\mathbf{I}}\left(\mathrm{u}_{2}, \mathrm{v}_{2}\right) * \mathrm{R}^{\mathbf{I}}\left(\mathrm{u}_{1}, \mathrm{u}_{2}\right) \leq \mathrm{R}^{\mathbf{I}}\left(\mathrm{v}_{1}, \mathrm{v}_{2}\right)$.

A fuzzy role inclusion axiom, or fuzzy RIA is an expression of the form

$$
\text { hw } \vee \text { R, ri, }
$$

where $\mathrm{w}=\mathrm{R}_{1} \cdot \ldots \cdot \mathrm{R}_{\mathrm{m}}$ is a role chain (i.e. a composition of roles). Given an interpretation $\mathbf{I}=h \Delta^{\mathbf{I}},(\cdot)^{\mathbf{I}}, * \mathbf{i}$, the interpretation of the composition is as follows: given $\mathrm{a}, \mathrm{b} \in \Delta^{\mathbf{I}}$,

$$
{ }^{\mathbf{I}}(\mathrm{a}, \mathrm{b})=\sup \left\{\mathrm{R}_{1}^{\mathbf{I}}\left(\mathrm{a}, \mathrm{c}_{1}\right) * \cdots * \mathrm{R}_{\mathrm{n}}^{\mathbf{I}}\left(\mathrm{c}_{\mathrm{n}-1}, \mathrm{~b}\right): \mathrm{c}_{1}, \ldots, \mathrm{c}_{\mathrm{n}-1} \in \Delta^{\mathbf{I}}\right\} .
$$

Then, the semantics for the fuzzy RIA hw $\vee$ R, ri is as follows:

$$
\mathbf{I} \models \mathrm{w} \vee \mathrm{R} \text { if and only if } \inf \left\{\mathrm{w}^{\mathbf{I}}(\mathrm{a}, \mathrm{b}) \underset{*}{\mathbf{I}} \mathrm{R}(\mathrm{a}, \mathrm{b}): \mathrm{a}, \mathrm{b} \in \Delta^{\mathbf{I}}\right\} \geq \mathrm{r} \text {. }
$$

Given an abstract role $\mathrm{S}$, the inverse role is denoted by $\mathrm{S}^{-}$, and given an interpretation $\mathbf{I}$, we have, for every $\mathrm{a}, \mathrm{b} \in \Delta^{\mathbf{I}}$,

$$
\left(\mathrm{S}^{-}\right)(\mathrm{a}, \mathrm{b})=\mathrm{S}^{\mathbf{I}}(\mathrm{b}, \mathrm{a})
$$

Finally, given an abstract role $S$, we can construct a concept, denoted by $\exists$ S. Self, whose semantics is given by the fuzzy set defined as

$$
(\exists \operatorname{S.Self})^{\mathbf{I}}(\mathrm{a})=\mathrm{S}^{\mathbf{I}}(\mathrm{a}, \mathrm{a}) .
$$

Observe that with all these resources we can express the axioms $\operatorname{ref}(\mathrm{S}), \operatorname{sym}(\mathrm{S})$, and trans(S) by means of inclusion axioms as it is shown in Table 4. We give only the justification of the equivalence between $\operatorname{trans}(S)$ and $h S \circ S \vee S, 1 i$ : Firstly, we have that $\mathbf{I} \models h \mathrm{~S} \cdot \mathrm{S} \vee \mathrm{S}, 1 \mathbf{i}$ is equivalent to say that the infimum of the set

$$
\left\{(\mathrm{S} \circ \mathrm{S})^{\mathbf{I}}(\mathrm{a}, \mathrm{b}) \Rightarrow_{\star} \mathrm{S}^{\mathbf{I}}(\mathrm{a}, \mathrm{b}): \mathrm{a}, \mathrm{b} \in \Delta^{\mathbf{I}}\right\}
$$


is equal to 1 , which is the same to say that $(S \circ S)^{\mathbf{I}}(a, b) \Rightarrow_{\star} S^{\mathbf{I}}(a, b)=1$, that is, $(S \circ S)^{\mathbf{I}}(a, b) \leq S^{\mathbf{I}}(a, b)$, for every $a, b \in \Delta^{\mathbf{I}}$. But this is equivalent to say that, for every $a, b \in \Delta^{\mathbf{I}}, \sup \left\{S^{\mathbf{I}}(a, c) * S^{\mathbf{I}}(c, b): c \in \Delta^{\mathbf{I}}\right\} \leq S^{\mathbf{I}}(a, b)$. This is trivially equivalent to say that, for every $a, b, c \in \Delta^{\mathbf{I}}, S^{\mathbf{I}}(a, c) * S^{\mathbf{I}}(c, b) \leq S^{\mathbf{I}}(a, b)$.

As we have stated before when we have introduced the interpretation of the axiom cong $(\mathrm{S})$, in order to express that an abstract role $\mathrm{S}$ is interpreted by a similarity which is a congruence, we need to express that the interpretations of every atomic concept and every atomic role are congruent with respect to the interpretation of S. This can be done by means of a set of general concept inclusions (one for every atomic concept) and a set of RIAs (one for every atomic role) as it is shown in the following propositions.

Proposition 4. Let A be an atomic concept, $\mathrm{S}$ be an abstract role, and $\mathbf{I}$ be an interpretation. The following conditions are equivalent:

a) $\mathbf{I} \models h A \vee \forall S . A, 1 \mathbf{i}$.

b) For every $a, b \in \Delta^{\mathbf{I}}, S^{\mathbf{I}}(a, b) * A^{\mathbf{I}}(a) \leq A^{\mathbf{I}}(b)$.

Proof: We have:

$$
\begin{array}{r}
\text { for every } \mathrm{a}, \mathrm{b} \in \Delta^{\mathbf{I}}, \mathrm{S}^{\mathbf{I}}(\mathrm{a}, \mathrm{b}) * \mathrm{~A}^{\mathbf{I}}(\mathrm{a}) \leq \mathrm{A}^{\mathbf{I}}(\mathrm{b}) \Leftrightarrow \\
\text { for every } \mathrm{a}, \mathrm{b} \in \Delta^{\mathbf{I}}, \mathrm{A}^{\mathbf{I}}(\mathrm{a}) \leq \mathrm{S}^{\mathbf{I}}(\mathrm{a}, \mathrm{b}) \Rightarrow_{*} \mathrm{~A}^{\mathbf{I}}(\mathrm{b}) \Leftrightarrow
\end{array}
$$$$
\text { for every } a \in \Delta^{\mathbf{I}}, \mathrm{A}^{\mathbf{I}}(\mathrm{a}) \leq \inf \left\{\mathrm{S}^{\mathbf{I}}(\mathrm{a}, \mathrm{b}) \Rightarrow_{\star} \mathrm{A}^{\mathbf{I}}(\mathrm{b}): \mathrm{b} \in \Delta^{\mathbf{I}}\right\} \quad \Leftrightarrow
$$$$
\text { for every a } \in \Delta^{\mathbf{I}}, \mathrm{A}^{\mathbf{I}}(\mathrm{a}) \leq(\forall \mathrm{S} . \mathrm{A})^{\mathbf{I}}(\mathrm{a}) \Leftrightarrow
$$$$
\text { for every a } \in \Delta^{\mathbf{I}}, \mathrm{A}^{\mathbf{I}}(\mathrm{a}) \Rightarrow_{*}(\forall \mathrm{S} . \mathrm{A})^{\mathbf{I}}(\mathrm{a})=1 \Leftrightarrow
$$$$
\inf \left\{\mathrm{A}^{\mathbf{I}}(\mathrm{a}) \Rightarrow_{*}(\forall \mathrm{S} . \mathrm{A})^{\mathbf{I}}(\mathrm{a}): \mathrm{a} \in \Delta^{\mathbf{I}}\right\}=1 \Leftrightarrow
$$

$$
\mathbf{I} \equiv h \mathrm{~A} \vee \forall \mathrm{S} . \mathrm{A}, 1 \mathbf{i} .
$$

First and fourth equivalences are given by the properties of residuation. The second and fifth ones are given by the properties of infima. The third one is given by the interpretation of $\forall$ S.A, and the last one by the interpretation of the axiom $h A \vee \forall S . A, 1 i$.

Proposition 5. Let $\mathrm{R}$ be an atomic role, $\mathrm{S}$ be an abstract role, and $\mathbf{I}$ be an interpretation satisfying the axioms $\operatorname{ref}(\mathrm{S})$ and $\operatorname{sym}(\mathrm{S})$. The following conditions are equivalent: 
a) $\mathbf{I}=\{h S \circ \mathrm{R} \vee \mathrm{R}, 1 \mathbf{i}, \mathrm{hR} \circ \mathrm{S} \vee \mathrm{R}, 1 \mathrm{i}\}$.

b) For every $a_{1}, a_{2}, b_{1}, b_{2} \in \Delta^{\mathbf{I}}, S^{\mathbf{I}}\left(a_{1}, b_{1}\right) * S^{\mathbf{I}}\left(a_{2}, b_{2}\right) * R^{\mathbf{I}}\left(a_{1}, a_{2}\right) \leq R^{\mathbf{I}}\left(b_{1}, b_{2}\right)$.

Proof: First we show that condition a) is equivalent to the fact that, for every $\mathrm{a}, \mathrm{b}, \mathrm{c} \in \Delta^{\mathbf{I}}$, these two conditions are satisfied:

$$
\begin{aligned}
& \mathrm{S}^{\mathbf{I}}(\mathrm{a}, \mathrm{c}) * \mathrm{R}^{\mathbf{I}}(\mathrm{c}, \mathrm{b}) \leq \mathrm{R}^{\mathbf{I}}(\mathrm{a}, \mathrm{b}), \\
& \mathrm{R}^{\mathbf{I}}(\mathrm{a}, \mathrm{c}) * \mathrm{~S}^{\mathbf{I}}(\mathrm{c}, \mathrm{b}) \leq \mathrm{R}^{\mathbf{I}}(\mathrm{a}, \mathrm{b}) .
\end{aligned}
$$

We have:

$$
\begin{aligned}
& \mathbf{I} \vDash h S \circ \mathrm{R} \vee \mathrm{R}, 1 \mathbf{i} \Leftrightarrow \\
& \inf \left\{(\mathrm{S} \circ \mathrm{R})^{\mathbf{I}}(\mathrm{a}, \mathrm{b}) \Rightarrow_{*} \mathrm{R}^{\mathbf{I}}(\mathrm{a}, \mathrm{b}): \mathrm{a}, \mathrm{b} \in \Delta^{\mathbf{I}}\right\}=1 \Leftrightarrow \\
& \text { for every } \mathrm{a}, \mathrm{b} \in \Delta^{\mathbf{I}},(\mathrm{S} \circ \mathrm{R})^{\mathbf{I}}(\mathrm{a}, \mathrm{b}) \Rightarrow_{\star} \mathrm{R}^{\mathbf{I}}(\mathrm{a}, \mathrm{b})=1 \Leftrightarrow \\
& \text { for every } \mathrm{a}, \mathrm{b} \in \Delta^{\mathbf{I}},(\mathrm{S} \circ \mathrm{R})^{\mathbf{I}}(\mathrm{a}, \mathrm{b}) \leq \mathrm{R}^{\mathbf{I}}(\mathrm{a}, \mathrm{b}) \Leftrightarrow \\
& \text { for every } \mathrm{a}, \mathrm{b} \in \Delta^{\mathbf{I}}, \sup \left\{\mathrm{S}^{\mathbf{I}}(\mathrm{a}, \mathrm{c})\right\} * \mathrm{R}^{\mathbf{I}}(\mathrm{c}, \mathrm{b}) \leq \mathrm{R}^{\mathbf{I}}(\mathrm{a}, \mathrm{b}) \quad \Leftrightarrow \\
& \text { for every } a, b, c \in \Delta^{\mathbf{I}}, S^{\mathbf{I}}(a, c) * R^{\mathbf{I}}(c, b) \leq R^{\mathbf{I}}(a, b) \text {. }
\end{aligned}
$$

In an analogous way we can show that $\mathbf{I} \models h S \cdot R \quad \mathbf{R}, 1 \mathbf{i}$ is equivalent to condition (2). Now we prove a) $\Rightarrow$ b): Let $a_{1}, a_{2}, b_{1}, b_{2} \in \Delta^{\mathbf{I}}$. By using conditions (1) and (2) we have:

$$
\begin{gathered}
S^{\mathbf{I}}\left(a_{1}, b_{1}\right) * S^{\mathbf{I}}\left(a_{2}, b_{2}\right) * R^{\mathbf{I}}\left(a_{1}, a_{2}\right)=S^{\mathbf{I}}\left(a_{1}, b_{1}\right) * R^{\mathbf{I}}\left(a_{1}, a_{2}\right) * S^{\mathbf{I}}\left(a_{2}, b_{2}\right) \leq \\
\leq S^{\mathbf{I}}\left(a_{1}, b_{1}\right) * R^{\mathbf{I}}\left(a_{1}, b_{2}\right) \leq S^{\mathbf{I}}\left(b_{1}, a_{1}\right) * R^{\mathbf{I}}\left(a_{1}, b_{2}\right) \leq R^{\mathbf{I}}\left(b_{1}, b_{2}\right) .
\end{gathered}
$$

To prove $b) \Rightarrow a$ ), we take $a_{1}=c, a_{2}=b, b_{1}=a, b_{2}=b$ in the inequality in $b$ ). We have:

$$
S^{\mathbf{I}}(c, a) * S^{\mathbf{I}}(b, b) * R^{\mathbf{I}}(c, b) \leq R^{\mathbf{I}}(a, b) .
$$

Now, by applying the properties of reflexivity and symmetry of $\mathrm{S}^{\mathbf{I}}$, we obtain condition (1). Finally, taking $\mathrm{a}_{1}=\mathrm{a}, \mathrm{a}_{2}=\mathrm{c}, \mathrm{b}_{1}=\mathrm{a}, \mathrm{b}_{2}=\mathrm{b}$ in the inequality in b), we have:

$$
\mathrm{S}^{\mathbf{I}}(\mathrm{a}, \mathrm{a}) * \mathrm{~S}^{\mathbf{I}}(\mathrm{c}, \mathrm{b}) * \mathrm{R}^{\mathbf{I}}(\mathrm{a}, \mathrm{c}) \leq \mathrm{R}^{\mathbf{I}}(\mathrm{a}, \mathrm{b}) .
$$

Now, by applying the reflexivity of $S^{\mathbf{I}}$ and the commutativity of *, we obtain condition (2). 
Proposition 6. Let $\mathrm{S}$ be an abstract role, and $\mathbf{I}$ be an interpretation satisfying the axioms $\operatorname{ref}(\mathrm{S})$ and $\operatorname{sym}(\mathrm{S})$. The following conditions are equivalent:

a) $\mathbf{I}=\operatorname{cong}(\mathrm{S})$.

b) For every atomic concept $A, \mathbf{I} \models h A \vee \forall S . A, 1 \mathbf{i}$, and, for every atomic role $\mathrm{R}, \mathbf{I}=\{\mathrm{hS} \circ \mathrm{R} \vee \mathrm{R}, 1 \mathrm{i}, \mathrm{hR} \cdot \mathrm{S} \vee \mathrm{R}, 1 \mathrm{i}\}$.

Proof: It is an immediate consequence of Propositions 4 and 5.

In an SBox we could also define similarities of two objects with respect to their attributes. In the next section we introduce global and local similarities.

\section{Local and global similarities in FDLs}

Global similarities between objects can be defined as the aggregation of local similarities (defined between values of the object's attributes). As references of the subject of aggregation operations see [27, 29, 50,61]. Important aggregation operators are t-norms and t-conorms. Using this kind of operations we can define global similarities in a multiplicative way as "fusion" of local similarities, or in an additive way as residuated sum of such local similarities.

An aggregation operator has the property of compensation (also known as Pareto property) when the result of the aggregation is lower than the maximum element aggregated and higher than the minimum one (see [27]). Some authors stress that t-norms (and also t-conorms) lack of a compensation behaviour, what is considered crucial in the aggregation process. In practice, when the property of compensation does not hold, this can produce undesirable effects when two objects are similar in all the attributes except in one of them. The operators known as uninorms [32] are a generalization of t-norms in which the neutral element of the operation does not coincide with the maximum. This characteristic implies that this kind of operations admit in general a good compensating behaviour. Since our primary focus is on integrating similarities in the context of Fuzzy Description Logics, we left for future work the extension of the results obtained in the present paper in the more general context of uninorms and other aggregation operators as OWA.

The representation of domain objects using sets of attribute-value pairs, the value of an attribute may be qualitative or quantitative (see [63] to clarify the classes of data types). In the next we recall how Description Logics use the so-called concrete domains in order to deal with domain objects represented by attribute-value pairs, and we present the languages ALC(D) of [47]. 
For instance, let us suppose that a person is described by the following attributes: age, hair, and height. Notice that these attributes are of different nature. Both age and height are numerical, however we can consider that the former is a natural number whereas the later is a rational number; and hair can take values into a finite set (sometimes this is called an enumerated type), for instance $\mathrm{V}=\{$ blonde, white, red, brown, black .

Let us illustrate with an example the difficulties we can encounter to deal with attribute-value representations in ALC.

Example 1. Let us suppose that we want to describe that an individual $p$ is 25 years old, his hair is blonde, and his height is $170 \mathrm{~cm}$. Using ALC we can express this attribute's value including in the TBox axioms like the following ones:

$>\mathbf{v}$ Hair_Blonde $\mathbf{t}$ Hair_White $\mathbf{t}$ Hair_Red $\mathbf{t}$ Hair_Brown $\mathbf{t}$ Hair_Black, Hair_Blonde $v$ Human, Hair_White $v$ Human, ... Hair_Blonde u Hair_White $v \perp$, Hair_Blonde $\mathrm{u}$ Hair_Red $v \perp$, Hair_Blonde u Hair_Brown $v \perp, \ldots$

Thus we use a concept for each one of the values in the set $\mathrm{V}$, and we need some axioms involving all these concepts. Moreover, in the ABox we have to include the axiom Hair_Blonde(p), expresing that $\mathrm{p}$ is an instance of the concept Hair_Blonde. However when we deal with attributes whose values belong to the sets of rational or natural numbers, this kind of solution is not possible, because these sets are infinite.

Example 2. Let us suppose that a person $\mathrm{p}$ is described using an attribute-value representation in the following way:

$$
\mathrm{p}=\mathrm{h}(\text { age, 25), (hair, blonde), (height, 170)i }
$$

For simplicity, let us focus on the attribute hair and assume that it is enumerated and it takes values in the set V mentioned before. Using ALC we can express this attribute's value including in the TBox the axioms:

$>$ v Hair_Blonde $\mathbf{t}$ Hair_White $\mathbf{t}$ Hair_Red $\mathbf{t}$ Hair_Brown $\mathbf{t}$ Hair_Black, Hair_Blonde $v$ Human, Hair_White $v$ Human, ...

Hair_Blonde u Hair_White $\vee \perp$, Hair_Blonde u Hair_Red $v \perp$, 
Hair_Blonde u Hair_Brown $v \perp, \ldots$

Thus we use a concept for each one of the values in the set $V$, and we need some axioms involving all these concepts. Moreover, in the ABox we have to include the axiom Hair_Blonde(p). However when we deal with attributes whose values belong to the sets of rational or natural numbers, this kind of solution is not possible, because these sets are infinite.

\subsection{Concrete Domains}

A natural and elegant way to deal in DLs with situations like the one of the previous example is by using the so-called concrete domains proposed by Baader and Hanschke in [5] (see complete references on the topic in [46, 47]). In the next we present the extension of ALC with concrete domains, denoted by ALC(D). For this presentation we follow the one in [7].

Formaly, a concrete domain $D$ is a pair $h \Delta_{D}, \Phi_{D} \mathbf{i}$, where $\Delta_{D}$ is a set and $\Phi_{D}$ is a set of predicate names. Each predicate name $\mathrm{P} \in \Phi_{\mathrm{D}}$ is associated with an arity $\mathrm{n}$ and an $\mathrm{n}$-ary predicate $\mathrm{P}^{\mathrm{D}} \leftrightharpoons \Delta_{\mathrm{D}}^{\mathrm{n}}$. Prominent examples of concrete domains are the numerical domains $\mathrm{N}$, or $\mathrm{Q}$. We describe $\mathrm{Q}$ (the description of $\mathrm{N}$ is analogous): the set $\Delta_{\mathrm{Q}}$ is the set of rational numbers $\mathrm{Q}$. The predicates are the following ones:

- binary predicates $<, \leq,=,=, \geq,>$ with the usual interpretation;

- unary predicates $\mathrm{P}_{\mathrm{q}}$ for every $\mathrm{P} \in\{<, \leq,=,=, \geq,>\}$ and every $\mathrm{q} \in \mathrm{Q}$, interpreted as $\left(\mathrm{P}_{\mathrm{q}}\right)^{\mathrm{Q}}=\left\{\mathrm{q}^{0} \in \mathrm{Q}: \mathrm{q}^{0} \mathrm{P} \mathrm{q}\right\}$;

- a ternary predicate + , with $+\mathrm{Q}=\left\{h \mathrm{q}, \mathrm{q}^{0}, \mathrm{q}^{00} \mathrm{i} \in \mathrm{Q}^{3}: \mathrm{q}+\mathrm{q}^{0}=\mathrm{q}^{00}\right\}$.

$A L C(D)$ is obtained from ALC by extending it with:

- abstract features that are roles interpreted as partial functions from $\Delta^{\mathbf{I}}$ to $\Delta^{\mathbf{I}}$; such features can be used inside both value and existential restrictions;

- concrete features that are roles interpreted as partial functions from $\Delta^{\mathbf{I}}$ to $\Delta_{D}$; such features can not be used inside both value and existential restrictions;

- a concept constructor $\exists \mathrm{u}_{1}, \ldots, \mathrm{u}_{\mathrm{n}} \cdot \mathrm{P}$, where $\mathrm{P} \in \Phi_{\mathrm{D}}$ is a predicate of arity $\mathrm{n}$, and every $\mathrm{u}_{\mathrm{i}}$ is a composition $\mathrm{f}_{1}, \ldots \cdot \mathrm{f}_{\mathrm{k}} \cdot \mathrm{g}$, being $\mathrm{f}_{1}, \ldots, \mathrm{f}_{\mathrm{k}}$ abstract 
features, and $g$ a concrete feature ${ }^{4}$. These composed expressions are called concrete paths. This new constructor is interpreted as follows:

$$
\begin{aligned}
& \left(\exists \mathrm{u}_{1}, \ldots, \mathrm{u}_{\mathrm{n}} \cdot \mathrm{P}\right)^{\mathbf{I}}=\left\{\mathrm{d} \in \Delta^{\mathbf{I}}: \text { there exist } \mathrm{x}_{1}, \ldots, \mathrm{x}_{\mathrm{n}} \in \Delta_{\mathrm{D}}\right. \text { such that } \\
& \quad \mathrm{u}_{1}^{\mathbf{I}}(\mathrm{d})=\mathrm{x}_{1}, \ldots, \mathrm{u}_{\mathrm{n}}^{\mathbf{I}}(\mathrm{d})=\mathrm{x}_{\mathrm{n}} \text { for } 1 \leq \mathrm{i} \leq \mathrm{n} \text { and } \mathrm{hx}_{1}, \ldots, \mathrm{x}_{\mathrm{n}} \mathrm{i} \in \mathrm{P} \quad \mathrm{D} .
\end{aligned}
$$

Let us consider a pair of examples. Firstly, let us suppose we want to define Young_People as a Human with age between 15 and 30. Using the concrete domain $\mathrm{D}$ of the natural numbers we can write:

$$
\text { Young_People } \equiv \text { Human } u \quad \exists(\text { age }) . \leq_{30} \cup \exists(\text { age }) . \geq_{15}
$$

where age is a concrete feature, a partial function from the domain $\Delta^{\mathbf{I}}$ into the concrete domain $\Delta^{\mathrm{D}}$ and $\geq_{15}$ and $\leq_{30}$ are predicate names of the concrete domain $\mathrm{D}$, interpreted as the set of natural numbers greater or equal than 15 and lower or equal than 30, respectively. As an example involving a predicate of arity 2, consider the concept 'human having a salary smaller than the one of his wife' that can be writen:

$$
\text { Human u Male u } \exists \text { (salary), (wife • salary). }<\text {, }
$$

where wife is an abstract feature and salary is a concrete feature.

\subsection{Fuzzy concrete domains}

A first fuzzy description logic with fuzzy concrete domais was introduced by Straccia in [58]. In this section we recap the fuzzy description logic with concrete domains IALCE F (D) defined by Bobillo and Straccia in [10]. ${ }^{5}$

IALCEF(D) extends the logic IALCE with functional roles and concrete domains allowing to deal with datatypes such as numbers or strings. In a similar way to the classical case, a fuzzy concrete domain $D$ is a pair $h \Delta_{D}, \Phi_{D} \mathbf{i}$, where $\Delta_{D}$ is a set disjoint with $\Delta^{\mathbf{I}}$, and $\Phi_{D}$ is a set of predicate names. But in the fuzzy setting, each predicate name $\mathrm{P} \in \Phi_{\mathrm{D}}$ is associated with an arity $\mathrm{n}$ and an n-ary fuzzy relation $\mathrm{P}^{\mathrm{D}}: \Delta_{\mathrm{D}}^{\mathrm{n}} \rightarrow[0,1]$.

Concrete domains integrated in IALCEF(D) are N, Q and a set of strings. These domains work as in the classical case. The presence of the strings set allows,

\footnotetext{
${ }^{4}$ In some papers, such as [7, 5], these constructor is denoted by $\mathrm{P}\left(\mathrm{u}_{1}, \ldots, \mathrm{u}_{\mathrm{n}}\right)$. We prefer the notation using ' $\exists$ ' for coherence with the notation used in the following section for the fuzzy case.

${ }^{5}$ The logic defined in [10] was denoted by ALCF (D), but following the notational conventions for fuzzy description logics stated in [8] we denote this logic as IALCEF(D).
} 


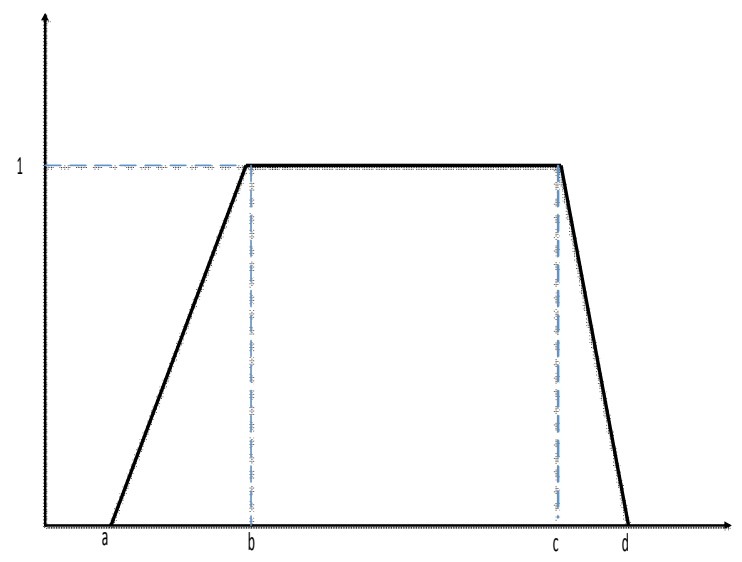

Figure 2: General trapezoidal function

for instance, by using the functional concrete role hasFamilyName, to express the concept of people whose family name is "Smith" as

\section{Human u JhasFamilyName. $={ }_{\text {Smith }}$}

Moreover, the definition of genuine fuzzy concrete predicates is done by adding to the integrated concrete domains the following families of functions defined on $\mathrm{Q}^{+} \cup\{0\}$ : trapezoidal, triangular, left-shoulder (L-functions), right-shoulder ( $\mathrm{R}$ functions), all used to specify membership degrees. In Figure 2 we have a generic trapezoidal function. These kind of functions have four parameters $a, b, c, d \in$ $\mathrm{Q}^{+} \cup\{0\}$, and they are defined as follows:

$$
\mathrm{T}(\mathrm{x} ; \mathrm{a}, \mathrm{b}, \mathrm{c}, \mathrm{d})=\begin{array}{ll}
0, & \text { if } \mathrm{x} \leq \mathrm{a} \\
\frac{\mathrm{x}+\mathrm{a}}{\mathrm{a}-\mathrm{b}}, & \text { if } \mathrm{a} \leq \mathrm{x} \leq \mathrm{b} \\
1, & \text { if } \mathrm{b} \leq \mathrm{x} \leq \mathrm{c} \\
\frac{\mathrm{x}-\mathrm{d}}{\mathrm{c}-\mathrm{d}}, & \text { if } \mathrm{c} \leq \mathrm{x} \leq \mathrm{d} \\
0, & \text { if } \mathrm{d} \leq \mathrm{x}
\end{array}
$$

When $\mathrm{a}<\mathrm{b}<\mathrm{c}<\mathrm{d}$ we obtain a genuine trapezoidal function. In the case $\mathrm{a}<\mathrm{b}=\mathrm{c}<\mathrm{d}$ we obtain triangular functions. L-functions arise in the case in which $0=\mathrm{a}=\mathrm{b}<\mathrm{c}<\mathrm{d}$, and we have R-functions when $\mathrm{a}<\mathrm{b}=\mathrm{c}=\mathrm{d}$. 
These functions allow us to define fuzzy concrete features as compositions of crisp concrete features with this kind of functions. Thus, for instance, from the concrete feature height we can define the fuzzy concrete feature youth as $\exists$ (height).P, where

$$
\mathrm{P}^{\mathrm{D}}(\mathrm{x})=\mathrm{L}(\mathrm{x} ; 160,190)=\begin{array}{ll}
\square 0, & \text { if } \mathrm{x} \leq 160 \\
\frac{10 \mathrm{x}-16}{3}, & \text { if } 160 \leq \mathrm{x} \leq 190 \\
1, & \text { if } 190 \leq \mathrm{x} .
\end{array}
$$

The description logic IALCE F (D), as it is presented in [10], also allows fuzzy modifiers like very, more or less and slightly. The interpretation of these modifiers are functions $f_{m}:[0,1]-\rightarrow[0,1]$ which are applied to fuzzy sets to change their membership function. For instance very and slightly can be interpreted, respectively, by

$$
\operatorname{very}^{\mathbf{I}}(\mathrm{x})=\mathrm{x}^{2}, \quad \operatorname{slightly}^{\mathbf{I}}(\mathrm{x})={ }^{\sqrt{ }} \overline{\mathrm{x}} .
$$

For further details about the syntax and semantics of IALCE F(D) see [10], where a tableau for every knowledge base for that description logic is given.

\subsection{Defining global and local similarities}

Let $U$ be a set of objects of the interpretation domain represented by attributevalue pairs. Let $V_{1}, \ldots, V_{k}$ be non-empty sets such that every object $u \in U$ is of the form $\mathrm{u}=h \mathrm{u}_{1}, \ldots, \mathrm{u}_{\mathrm{k}} \mathrm{i}$, where $\mathrm{u}_{\mathrm{i}} \in \mathrm{V}_{\mathrm{i}}$ for every $\mathrm{i}, 1 \leq \mathrm{i} \leq \mathrm{k}$.

For every $i, 1 \leq \mathrm{i} \leq \mathrm{k}$, let $\mathrm{s}_{\mathrm{i}}$ be a binary fuzzy relation defined on $\mathrm{V}_{\mathrm{i}}$. Each relation $s_{i}$ induces a relation $r_{i}$ on $U$ as follows. For every $u, v \in U$, $\mathrm{u}=h \mathrm{u}_{1}, \ldots, \mathrm{u}_{\mathrm{k}} \mathbf{i}$ and $\mathrm{v}=\mathrm{hv}_{1}, \ldots, \mathrm{v}_{\mathrm{k}} \mathbf{i}$, we define:

$$
\mathrm{r}_{\mathrm{i}}(\mathrm{u}, \mathrm{v}) \equiv_{\mathrm{df}} \mathrm{s}_{\mathrm{i}}\left(\mathrm{u}_{\mathrm{i}}, \mathrm{v}_{\mathrm{i}}\right) .
$$

We call each $r_{i}$ a local relation. From these local relations, and using a t-norm *, we define a new relation s as follows:

$$
\mathrm{r}(\mathrm{u}, \mathrm{v}) \equiv_{\mathrm{df}} \mathrm{r}_{1}(\mathrm{u}, \mathrm{v}) * \cdots * \mathrm{r}_{\mathrm{k}}(\mathrm{u}, \mathrm{v}) .
$$

We say that $\mathbf{r}$ is a global relation.

Example 3. Table 5 shows the description of three persons according the degree they like three hobbies: trekking, reading, and cinema. In order to compare them we have to define a measure of how similar are two of these values. Let us suppose that we use the following formula to establish the similarity between two values:

$$
\mathrm{r}_{\mathrm{i}}(\mathrm{u}, \mathrm{v})=1-\left|\mathrm{u}_{\mathrm{i}}-\mathrm{v}_{\mathrm{i}}\right| \text {. }
$$




\begin{tabular}{c|c|c|c|}
\hline Name & trekking & reading & cinema \\
\hline John & 0.5 & 0.3 & 0.9 \\
Mary & 0.6 & 0.8 & 0.7 \\
Peter & 0.9 & 0.5 & 0.4
\end{tabular}

Table 5: Descriptions of three persons using the attributes trekking, reading, and cinema.

Now we use this expression to calculate the similarity between all the hobbies. For instance, concerning trekking John, Mary and Peter have the following degrees of similarity:

$$
\begin{aligned}
& \mathbf{r}_{\mathrm{t}}(\text { John, Mary })=1-|0.5-0.6|=0.9 \\
& \mathbf{r}_{\mathrm{r}}(\text { John, Peter })=1-|0.5-0.9|=0.6 \\
& \left.r_{c} \text { (Mary, Peter }\right)=1-|0.6-0.9|=0.7
\end{aligned}
$$

Expressed as matrices the relations trekking $\left(r_{t}\right)$, reading $\left(r_{r}\right)$, and cinema $\left(r_{c}\right)$ are the following:

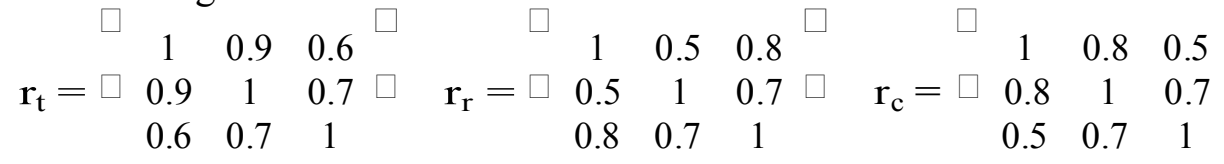

The global relation is $r(u, v) \equiv_{d f} r_{t}(u, v) * r_{r}(u, v) * r_{c}(u, v)$ and its general term is given by $a_{i j}=a_{i j}^{t} * a_{i j}^{r} * a_{i j}^{c}$, where $a_{i j}^{t}, a_{i j}^{r}$ and $a_{i j}^{c}$ stand for the element $(i, j)$ of the matrices $r_{t}, r_{r}$ and $r_{c}$, respectively. If we consider that $*$ is the minimum t-norm we have:

$$
\mathbf{r}_{\text {min }}=\square \begin{array}{ccc}
1 & 0.5 & 0.5 \\
0.5 & 1 & 0.7 \\
0.5 & 0.7 & 1
\end{array}
$$

and, considering that $*$ is the Łukasiewicz t-norm, we have:

$$
\mathrm{r}_{\mathrm{E}}=\square \begin{array}{ccc}
1 & 0.2 & 0 \\
0.2 & 1 & 0.1 \\
0 & 0.1 & 1
\end{array}
$$

Relations $r_{t}, r_{r}$ and $r_{c}$ are reflexive and symmetric since all the elements in the diagonal of the matrices are 1 and the matrices are all symmetric. Also, the matrices representing the global similarity taking both the minimum t-norm $\left(r_{\min }\right)$ and the Eukasiewicz t-norm $\left(r_{t}\right)$ have 1 in the diagonal and are symmetric. The 
relations $r_{t}, r_{r}$ and $r_{c}$ are not transitive if we take the minimum t-norm. To see this, we must see that there are some elements $\mathrm{x}, \mathrm{y}, \mathrm{z}$ such that for the relations $r_{t}, r_{r}, r_{c}$, the inequalities $R(x, y) * R(y, z) \leq R(x, z)$ are not satisfied. Indeed,

- $r_{\mathrm{t}}($ John, Mary $) * r_{t}($ Mary, Peter $) \quad r_{t}($ John, Peter $)$, since $\min \{0.9,0.7\}=0.7$ and $r_{\mathrm{t}}(\mathrm{John}$, Peter $)=0.6$,

- $r_{r}($ John, Peter $) * r_{r}$ (Peter, Mary) $r_{r}($ John, Mary $)$, since $\min \{0.8,0.7\}=0.7$ and $r_{r}($ John, Mary $)=0.5$,

- $\mathrm{r}_{\mathrm{c}}($ John, Mary $) * \mathrm{r}_{\mathrm{c}}$ (Mary, Peter $) \quad \mathrm{r}_{\mathrm{c}}($ John, Peter $)$, since $\min \{0.8,0.7\}=0.7$ and $r_{c}($ John, Peter $)=0.5$.

Taking the Łukasiewicz t-norm, it is not difficult to see that all of them $r_{t}, r_{r}$ and $r_{c}$ are transitive.

In the previous example we have given three local relations that are reflexive and symmetric and which also are transitive when we take Łukasiewicz t-norm. We also have seen that the aggregation of this three local relations by using the t-norm of Łukasiewicz is also reflexive, symmetric and transitive. In the next proposition we prove that this is a general fact.

Lemma 2. Let $U$ be a set of objects represented by attribute-value pairs. Let $\alpha_{1}, \ldots, \alpha_{k}$ be the attributes used to describe the objects in U. Suppose that every attribute $\alpha_{i}$ takes values in a set $V_{i}$. Let $r$ be the global relation induced by the local fuzzy relations $s_{1}, \ldots, s_{k}$ defined on $V_{1}, \ldots, V_{k}$, respectively. That is,

$$
\mathrm{r}(\mathrm{u}, \mathrm{v})=\mathrm{s}_{1}\left(\mathrm{u}_{1}, \mathrm{v}_{1}\right) * \cdots * \mathrm{~s}_{\mathrm{k}}\left(\mathrm{u}_{\mathrm{k}}, \mathrm{v}_{\mathrm{k}}\right)
$$

for every objects $u, v \in U$ represented by tuples $u=h u_{1} \ldots u_{k} \mathbf{i}$ and $v=h v_{1} \ldots v_{k} i$, respectively. Then, the following conditions hold:

1. If for every $\mathrm{i}, 1 \leq \mathrm{i} \leq \mathrm{k}, \mathrm{s}_{\mathrm{i}}$ is reflexive, then $\mathrm{r}$ is also reflexive.

2. If for every $\mathrm{i}, 1 \leq \mathrm{i} \leq \mathrm{k}, \mathrm{s}_{\mathrm{i}}$ is symmetric, then $\mathrm{r}$ is also symmetric.

3. If for every $\mathrm{i}, 1 \leq \mathrm{i} \leq \mathrm{k}, \mathrm{s}_{\mathrm{i}}$ is transitive, then $\mathrm{r}$ is also transitive.

Proof: Let $\mathrm{u}, \mathrm{v}, \mathrm{w} \in \mathrm{U}$ be objects represented as tuples $h \mathrm{u}_{1}, \ldots, \mathrm{u}_{\mathrm{k}} \mathbf{i}, h_{\mathrm{v}_{1}}, \ldots, \mathrm{v}_{\mathrm{k}} \mathbf{i}$ and $h_{w_{1}}, \ldots, w_{k} i$, respectively.

1. Assume that for every $\mathrm{i}, 1 \leq \mathrm{i} \leq \mathrm{k}, \mathrm{s}_{\mathrm{i}}$ is reflexive, that is, $\mathrm{s}_{\mathrm{i}}\left(\mathrm{u}_{\mathrm{i}}, \mathrm{u}_{\mathrm{i}}\right)=1$ for every $u_{i} \in V_{i}$. Therefore, by definition of $s$ and the fact that 1 is the neutral element of $*$, we have $\mathrm{r}(\mathrm{u}, \mathrm{u})=1$. Thus $\mathrm{s}$ is also reflexive. 
2. Assume that for every $\mathrm{i}, 1 \leq \mathrm{i} \leq \mathrm{k}, \mathrm{s}_{\mathrm{i}}$ is symmetric, that is, for every $\mathrm{u}_{\mathrm{i}}, \mathrm{v}_{\mathrm{i}} \in$ $\mathrm{V}_{\mathrm{i}}, \mathrm{s}_{\mathrm{i}}\left(\mathrm{u}_{\mathrm{i}}, \mathrm{v}_{\mathrm{i}}\right)=\mathrm{s}_{\mathrm{i}}\left(\mathrm{v}_{\mathrm{i}}, \mathrm{u}_{\mathrm{i}}\right)$. Therefore, by definition of $\mathrm{s}$ and basic properties of $*$, $\mathrm{s}(\mathrm{o}, \mathrm{u})=\mathrm{s}(\mathrm{u}, \mathrm{o})$. Thus $\mathrm{s}$ is also symmetric.

3. Assume that for every $i, s_{i}$ is transitive, that is, for every $u_{i}, v_{i}, w_{i} \in V_{i}$,

$$
\mathrm{s}_{\mathrm{i}}\left(\mathrm{u}_{\mathrm{i}}, \mathrm{v}_{\mathrm{i}}\right) * \mathrm{~s}_{\mathrm{i}}\left(\mathrm{v}_{\mathrm{i}}, \mathrm{w}_{\mathrm{i}}\right) \leq \mathrm{s}_{\mathrm{i}}\left(\mathrm{u}_{\mathrm{i}}, \mathrm{w}_{\mathrm{i}}\right) .
$$

By monotonicity of * and using the facts that $s_{1}$ and $s_{2}$ are transitive, we have:

$$
\mathrm{s}_{1}\left(\mathrm{u}_{1}, \mathrm{v}_{1}\right) * \mathrm{~s}_{1}\left(\mathrm{v}_{1}, \mathrm{w}_{1}\right) * \mathrm{~s}_{2}\left(\mathrm{u}_{2}, \mathrm{v}_{2}\right) * \mathrm{~s}_{2}\left(\mathrm{v}_{2}, \mathrm{w}_{2}\right) \leq \mathrm{s}_{1}\left(\mathrm{u}_{1}, \mathrm{w}_{1}\right) * \mathrm{~s}_{2}\left(\mathrm{u}_{2}, \mathrm{w}_{2}\right) .
$$

By iteration of this procedure we obtain:

$$
\begin{gathered}
\left(\mathrm{s}_{1}\left(\mathrm{u}_{1}, \mathrm{v}_{1}\right) * \mathrm{~s}_{1}\left(\mathrm{v}_{1}, \mathrm{w}_{1}\right)\right) * \cdots *\left(\mathrm{~s}_{\mathrm{k}}\left(\mathrm{u}_{\mathrm{k}}, \mathrm{v}_{\mathrm{k}}\right) * \mathrm{~s}_{\mathrm{k}}\left(\mathrm{v}_{\mathrm{k}}, \mathrm{w}_{\mathrm{k}}\right)\right) \leq \\
\leq \mathrm{s}_{1}\left(\mathrm{u}_{1}, \mathrm{w}_{1}\right) * \cdots * \mathrm{~s}_{\mathrm{k}}\left(\mathrm{u}_{\mathrm{k}}, \mathrm{w}_{\mathrm{k}}\right) .
\end{gathered}
$$

Finally, using commutativity of *, we have:

$$
\begin{gathered}
\left(\mathrm{s}_{1}\left(\mathrm{u}_{1}, \mathrm{v}_{1}\right) * \cdots * \mathrm{~s}_{\mathrm{k}}\left(\mathrm{u}_{\mathrm{k}}, \mathrm{v}_{\mathrm{k}}\right)\right) *\left(\mathrm{~s}_{1}\left(\mathrm{v}_{1}, \mathrm{w}_{1}\right) * \cdots * \mathrm{~s}_{\mathrm{k}}\left(\mathrm{v}_{\mathrm{k}}, \mathrm{w}_{\mathrm{k}}\right)\right) \leq \\
\leq \mathrm{s}_{1}\left(\mathrm{u}_{1}, \mathrm{w}_{1}\right) * \cdots * \mathrm{~s}_{\mathrm{k}}\left(\mathrm{u}_{\mathrm{k}}, \mathrm{w}_{\mathrm{k}}\right) .
\end{gathered}
$$

But, by definition of $\mathrm{s}$, this is equal to say $\mathrm{s}(\mathrm{u}, \mathrm{v}) * \mathrm{~s}(\mathrm{v}, \mathrm{w}) \leq \mathrm{s}(\mathrm{u}, \mathrm{w})$ and we can conclude that $\mathrm{s}$ is transitive.

When the global similarity is reflexive, using the integrality property of $*$ it is easy to show that the local similarities are also reflexive. Nevertheless, this is not true neither for symmetry nor for transitivity, as it is shown in the following two examples.

Example 4. Take the universe $U=\{\mathrm{u}, \mathrm{v}\}$ and suppose that the objects are described with two attributes being $u=h u_{1}, u_{2} \mathbf{i}$ and $v=h v_{1}, v_{2} i$. Let $s$ be the global similarity induced by two local similarities $s_{1}$ and $s_{2}$ defined in the sets of values of the respective attributes in such a way that

$$
\mathrm{s}_{2}\left(\mathrm{v}_{2}, \mathrm{u}_{2}\right)=\mathrm{s}_{1}\left(\mathrm{u}_{1}, \mathrm{v}_{1}\right)=\mathrm{s}_{1}\left(\mathrm{v}_{1}, \mathrm{u}_{1}\right)=\mathrm{s}_{2}\left(\mathrm{u}_{2}, \mathrm{v}_{2}\right) .
$$

So defined $s_{1}$ and $s_{2}$ are not symmetric. But we have:

$$
\mathrm{s}(\mathrm{u}, \mathrm{v})=\mathrm{s}_{1}\left(\mathrm{u}_{1}, \mathrm{v}_{1}\right) * \mathrm{~s}_{2}\left(\mathrm{u}_{2}, \mathrm{v}_{2}\right)=\mathrm{s}_{2}\left(\mathrm{v}_{2}, \mathrm{u}_{2}\right) * \mathrm{~s}_{1}\left(\mathrm{v}_{1}, \mathrm{u}_{1}\right)=\mathrm{s}(\mathrm{v}, \mathrm{u}) .
$$

Thus, the global relation is symmetric. 
Example 5. Take the universe $U=\{\mathrm{u}, \mathrm{v}, \mathrm{w}\}$ and suppose that objects are described with two attributes being $\mathbf{u}=h_{u_{1}}, \mathbf{u}_{2} \mathbf{i}, \mathbf{v}=h_{v_{1}}, v_{2} \mathbf{i}$, and $\mathrm{w}=h_{\mathrm{w}_{1}}, \mathrm{w}_{2} \mathbf{i}$. Assume that $*$ is the minimum $t$-norm, and let $\mathrm{s}$ be the global similarity induced by two local similarities $s_{1}$ and $s_{2}$ defined in the sets of values of the respective attributes in such a way that

$$
\begin{array}{lll}
\mathrm{s}_{1}\left(\mathrm{u}_{1}, \mathrm{v}_{1}\right)=0.2 & \mathrm{~s}_{1}\left(\mathrm{v}_{1}, \mathrm{w}_{1}\right)=0.4 & \mathrm{~s}_{1}\left(\mathrm{u}_{1}, \mathrm{w}_{1}\right)=0.1 \\
\mathrm{~s}_{2}\left(\mathrm{u}_{2}, \mathrm{v}_{2}\right)=0.5 & \mathrm{~s}_{2}\left(\mathrm{v}_{2}, \mathrm{w}_{2}\right)=0 & \mathrm{~s}_{2}\left(\mathrm{u}_{2}, \mathrm{w}_{2}\right)=0.1 .
\end{array}
$$

Observe that $\mathrm{s}_{1}$ is not transitive $\operatorname{since} \min \left(\mathrm{s}_{1}\left(\mathrm{u}_{1}, \mathrm{v}_{1}\right), \mathrm{s}_{1}\left(\mathrm{v}_{1}, \mathrm{w}_{1}\right)\right)=0.2>0.1=$ $\mathrm{s}_{1}\left(\mathrm{u}_{1}, \mathrm{w}_{1}\right)$. But we have:

$$
\begin{gathered}
\mathrm{s}(\mathrm{u}, \mathrm{v}) * \mathrm{~s}(\mathrm{v}, \mathrm{w})=\mathrm{s}_{1}\left(\mathrm{u}_{1}, \mathrm{v}_{1}\right) * \mathrm{~s}_{2}\left(\mathrm{u}_{2}, \mathrm{v}_{2}\right) * \mathrm{~s}_{1}\left(\mathrm{v}_{1}, \mathrm{w}_{1}\right) * \mathrm{~s}_{2}\left(\mathrm{v}_{2}, \mathrm{w}_{2}\right)= \\
=0.2 * 0=0 \leq \mathrm{s}(\mathrm{u}, \mathrm{w}) .
\end{gathered}
$$

Thus, the global relation is transitive.

\section{A general result on global similarities}

Hájek in [35, Lemma 5.6.8] proved, in the context of the logic BL $\forall$, that similar objects have similar properties, being these properties expressed by firstorder formulas evaluated in these objects. In the following we generalize this result to the logic MTL $\forall$. To present this result, we extend the notion of syntactic degree of a formula in [35, Definition 5.6.7] to the language of MTL $\forall$ in the following way:

1. $\operatorname{dg}(\varphi)=1$, if $\varphi$ is atomic,

2. $\operatorname{dg}(\varphi)=0$, if $\varphi$ is a truth constant,

3. $\operatorname{dg}(\forall x \varphi)=\operatorname{dg}(\exists x \varphi)=\operatorname{dg}(\neg \varphi)=\operatorname{dg}(\varphi)$,

4. $\operatorname{dg}(\varphi \rightarrow \psi)=\operatorname{dg}(\varphi \& \psi)=\operatorname{dg}(\varphi)+\operatorname{dg}(\psi)$,

5. $\operatorname{dg}(\varphi \wedge \psi)=\max \{\operatorname{dg}(\varphi), \operatorname{dg}(\psi)\}$.

Notation: Let $\mathrm{x} \approx^{\mathrm{k}} \mathrm{y}$ abbreviate $(\mathrm{x} \approx \mathrm{y}) \& \cdots \&(\mathrm{x} \approx \mathrm{y})(\mathrm{k}$ times $)$.

Theorem 1. Let $\mathrm{T}$ be a theory in MTL $\forall$ containing the axioms:

(S1) $(\forall \mathrm{x}) \mathrm{x} \approx \mathrm{x}$

(Reflexivity)

(S2) $(\forall \mathrm{x}, \mathrm{y})(\mathrm{x} \approx \mathrm{y} \rightarrow \mathrm{y} \approx \mathrm{x})$

(Symmetry)

(S3) $(\forall \mathrm{x}, \mathrm{y}, \mathrm{z})(\mathrm{x} \approx \mathrm{y} \& \mathrm{y} \approx \mathrm{z} \rightarrow \mathrm{x} \approx \mathrm{z})$

(Transitivity) 
and, for every $n$-ary predicate $\mathrm{P}$ and every k-ary functional $\mathrm{f}$ in the language, the congruence axioms:

$$
\begin{aligned}
& (\text { Cong })_{\mathrm{P}} \quad\left(\forall \mathrm{x}_{1}, \ldots, \mathrm{x}_{\mathrm{n}}, \mathrm{y}_{1}, \ldots, \mathrm{y}_{\mathrm{n}}\right)\left(\mathrm{x}_{1} \approx \mathrm{y}_{1} \& \cdots \& \mathrm{x}_{\mathrm{n}} \approx \mathrm{y}_{\mathrm{n}} \rightarrow\right. \\
& \left.\rightarrow\left(\mathrm{P} \mathrm{x}_{1}, \ldots, \mathrm{x}_{\mathrm{n}} \leftrightarrow \mathrm{P}_{1}, \ldots, \mathrm{y}_{\mathrm{n}}\right)\right) . \\
& (\text { Cong })_{\mathrm{f}} \quad\left(\forall \mathrm{x}_{1}, \ldots, \mathrm{x}_{\mathrm{k}}, \mathrm{y}_{1}, \ldots, \mathrm{y}_{\mathrm{k}}\right)\left(\mathrm{x}_{1} \approx \mathrm{y}_{1} \& \cdots \& \mathrm{x}_{\mathrm{k}} \approx \mathrm{y}_{\mathrm{k}} \rightarrow\right. \\
& \left.\rightarrow\left(f x_{1}, \ldots, x_{k} \approx f y_{1}, \ldots, y_{k}\right)\right) \text {. }
\end{aligned}
$$

Let $\varphi$ be a first-order formula of $\operatorname{MTL} \forall$ with $\operatorname{dg}(\varphi)=k$, and let $x_{1} \ldots, x_{n}$ be variables including all free variables of $\varphi$ in such a way that, for every $1 \leq \mathrm{i} \leq \mathrm{n}$, $y_{i}$ is substituable for $x_{i}$ in $\varphi$. Then,

$$
\mathrm{T}^{-}\left(\mathrm{x}_{1} \approx^{\mathrm{k}} \mathrm{y}_{1}\right) \& \cdots \&\left(\mathrm{x}_{\mathrm{n}} \approx^{\mathrm{k}} \mathrm{y}_{\mathrm{n}}\right) \rightarrow\left(\varphi\left(\mathrm{x}_{1}, \ldots, \mathrm{x}_{\mathrm{n}}\right) \leftrightarrow \varphi\left(\mathrm{y}_{1}, \ldots, \mathrm{y}_{\mathrm{n}}\right)\right) .
$$

Proof: By induction on the complexity of formulas. By the congruence and similarity axioms, the assertion is true for atomic formulas (and is vacuous for truth constants). For the sake of clarity, we will proof the inductive steps (except for the $\forall$ and $\exists$ steps) only for 2 variables, that is, for $\mathrm{x} \approx^{\mathrm{k}} \mathrm{y}$ instead that for $\left(\mathrm{x}_{1} \approx^{\mathrm{k}} \mathrm{y}_{1}\right) \& \cdots \&\left(\mathrm{x}_{\mathrm{n}} \approx^{\mathrm{k}} \mathrm{y}_{\mathrm{n}}\right)$. The generalization to the $\mathrm{n}$ case is trivial. Now assume that the property holds for the formulas $\varphi(\mathrm{x})$ and $\psi(\mathrm{x})$, with $\operatorname{dg}(\varphi)=\mathrm{k}$ and $\operatorname{dg}(\psi)=\mathrm{h}$.

Inductive step $\varphi \& \psi$. By definition of the syntactic degree, $\operatorname{dg}(\varphi \& \psi)=\mathrm{k}+\mathrm{h}$. By the inductive hypothesis we have:

and

$$
\mathrm{T}-\mathrm{x} \approx^{\mathrm{k}} \mathrm{y} \rightarrow(\varphi(\mathrm{x}) \leftrightarrow \varphi(\mathrm{y})),
$$

$$
\mathrm{T}^{-\mathrm{x}} \approx^{\mathrm{h}} \mathrm{y} \rightarrow(\psi(\mathrm{x}) \leftrightarrow \psi(\mathrm{y})) .
$$

In MTL holds that T $\alpha$ and $\mathrm{T}^{-} \beta$ implies T $\alpha \& \beta$. Thus, we have:

$$
\mathrm{T}^{-}\left(\mathrm{x} \approx^{\mathrm{k}} \mathrm{y} \rightarrow(\varphi(\mathrm{x}) \leftrightarrow \varphi(\mathrm{y}))\right) \&\left(\mathrm{x} \approx^{\mathrm{h}} \mathrm{y} \rightarrow(\psi(\mathrm{x}) \leftrightarrow \psi(\mathrm{y}))\right),
$$

and then, by Proposition 2(3),

$$
\mathrm{T}^{-} \mathrm{x} \approx^{\mathrm{k}+\mathrm{h}} \mathrm{y} \rightarrow(\varphi(\mathrm{x}) \leftrightarrow \varphi(\mathrm{y})) \&((\psi(\mathrm{x}) \leftrightarrow \psi(\mathrm{y})) .
$$

By definition of $\leftrightarrow$, axiom (MTL3), and Proposition 2(1,2),

$$
\mathrm{T}^{-\mathrm{x}} \approx^{\mathrm{k}+\mathrm{h}} \mathrm{y} \rightarrow
$$




$$
\rightarrow[(\varphi(\mathrm{x}) \rightarrow \varphi(\mathrm{y})) \&(\psi(\mathrm{x}) \rightarrow \psi(\mathrm{y}))] \&[(\varphi(\mathrm{y}) \rightarrow \varphi(\mathrm{x})) \&((\psi(\mathrm{y}) \rightarrow \psi(\mathrm{x}))],
$$

and, by Proposition 2(3),

$$
\mathrm{T}^{-\mathrm{x}} \approx^{\mathrm{k}+\mathrm{h}} \mathrm{y} \rightarrow
$$

$\rightarrow[(\varphi(\mathrm{x}) \& \psi(\mathrm{x})) \rightarrow(\varphi(\mathrm{y}) \& \psi(\mathrm{y}))] \&[(\varphi(\mathrm{y}) \& \psi(\mathrm{y})) \rightarrow(\varphi(\mathrm{x}) \& \psi(\mathrm{x}))]$.

Therefore, by definition of $\leftrightarrow$,

$$
\mathrm{T}^{-} \mathrm{x} \approx^{\mathrm{k}+\mathrm{h}} \mathrm{y} \rightarrow[(\varphi(\mathrm{x}) \& \psi(\mathrm{x})) \leftrightarrow(\varphi(\mathrm{y}) \& \psi(\mathrm{y}))] .
$$

Inductive step $\varphi \rightarrow \psi$. By definition of syntactic degree, $\operatorname{dg}(\varphi \& \psi)=\mathrm{k}+\mathrm{h}$. By inductive hypothesis we have:

and

$$
\mathrm{T}^{-\mathrm{x}} \approx^{\mathrm{k}} \mathrm{y} \rightarrow(\varphi(\mathrm{x}) \leftrightarrow \varphi(\mathrm{y})),
$$

$$
\mathrm{T}^{-} \mathrm{x} \approx^{\mathrm{h}} \mathrm{y} \rightarrow(\psi(\mathrm{x}) \leftrightarrow \psi(\mathrm{y})) .
$$

Proceeding as in the $\&$ case, we obtain:

$$
\mathrm{T}^{-} \mathrm{x} \approx^{\mathrm{k}+\mathrm{h}} \mathrm{y} \rightarrow(\varphi(\mathrm{x}) \leftrightarrow \varphi(\mathrm{y})) \&((\psi(\mathrm{x}) \leftrightarrow \psi(\mathrm{y})) .
$$

By Proposition 2(4),

$$
(\varphi(\mathrm{x}) \leftrightarrow \varphi(\mathrm{y})) \rightarrow[(\varphi(\mathrm{x}) \rightarrow \psi(\mathrm{x})) \leftrightarrow(\varphi(\mathrm{y}) \rightarrow \psi(\mathrm{x}))],
$$

and, by Proposition 2(5),

$$
\text { - }(\psi(\mathrm{x}) \leftrightarrow \psi(\mathrm{y})) \rightarrow[(\varphi(\mathrm{y}) \rightarrow \psi(\mathrm{x})) \leftrightarrow(\varphi(\mathrm{y}) \rightarrow \psi(\mathrm{y}))] .
$$

Thus, by Proposition 2(6), we can conclude that

$$
\mathrm{T}^{-} \mathrm{x} \approx^{\mathrm{k}+\mathrm{h}} \mathrm{y} \rightarrow[(\varphi(\mathrm{x}) \rightarrow \psi(\mathrm{x})) \leftrightarrow(\varphi(\mathrm{y}) \rightarrow \psi(\mathrm{y}))] .
$$

Inductive step $\varphi \wedge \psi$. By definition of the syntactic degree, $\operatorname{dg}(\varphi \wedge \psi)=$ $\max (\operatorname{dg}(\varphi), \operatorname{dg}(\psi))$. Without lost of generality, assume that $\mathrm{k} \leq \mathrm{h}$. By inductive hypothesis we have:

$$
\mathrm{T}^{-} \mathrm{x} \approx^{\mathrm{k}} \mathrm{y} \rightarrow(\varphi(\mathrm{x}) \leftrightarrow \varphi(\mathrm{y})),
$$

and

$$
\mathrm{T}^{-} \mathrm{x} \approx^{\mathrm{h}} \mathrm{y} \rightarrow(\psi(\mathrm{x}) \leftrightarrow \psi(\mathrm{y})) .
$$


Since $\mathrm{k} \leq \mathrm{h}$, by axiom (MTL2), we have that the formula $\mathrm{x} \approx^{\mathrm{h}} \mathrm{y} \rightarrow \mathrm{x} \approx^{\mathrm{k}} \mathrm{y}$ is a theorem of MTL. Then,

$$
\mathrm{T}^{-} \mathrm{x} \approx^{\mathrm{h}} \mathrm{y} \rightarrow(\varphi(\mathrm{x}) \leftrightarrow \varphi(\mathrm{y})),
$$

and

$$
\mathrm{T}^{-} \mathrm{x} \approx^{\mathrm{h}} \mathrm{y} \rightarrow(\psi(\mathrm{x}) \leftrightarrow \psi(\mathrm{y})) .
$$

In MTL holds that T ${ }^{-} \alpha$ and $\mathrm{T}^{-} \beta$ implies T $\alpha \wedge \beta$. Thus, we have

$$
\mathrm{T}^{-}\left(\mathrm{x} \approx^{\mathrm{h}} \mathrm{y} \rightarrow(\varphi(\mathrm{x}) \leftrightarrow \varphi(\mathrm{y}))\right) \wedge\left(\mathrm{x} \approx^{\mathrm{h}} \mathrm{y} \rightarrow(\psi(\mathrm{x}) \leftrightarrow \psi(\mathrm{y}))\right),
$$

and then by Proposition 2(7),

$$
\mathrm{T}^{\top} \mathrm{x} \approx \approx^{\mathrm{h}} \mathrm{y} \rightarrow[(\varphi(\mathrm{x}) \leftrightarrow \varphi(\mathrm{y})) \wedge(\psi(\mathrm{x}) \leftrightarrow \psi(\mathrm{y}))],
$$

and, by definition of $\leftrightarrow$,

$$
\mathrm{T}^{-} \mathrm{x} \approx \approx^{\mathrm{h}} \mathrm{y} \rightarrow
$$

$\rightarrow[(\varphi(\mathrm{x}) \rightarrow \varphi(\mathrm{y})) \&(\varphi(\mathrm{y}) \rightarrow \varphi(\mathrm{x}))] \wedge[(\psi(\mathrm{x}) \rightarrow \psi(\mathrm{y})) \&((\psi(\mathrm{y}) \rightarrow \psi(\mathrm{x}))]$.

Now, we will use the fact holds in MTL:

$$
\mathrm{T}^{-} \alpha \rightarrow(\beta \wedge \gamma) \text { and } \mathrm{T}^{-} \beta \rightarrow \delta \text { and } \mathrm{T}^{`} \gamma \rightarrow \text { implies } \mathrm{T}^{`} \alpha \rightarrow(\delta \wedge) \text {. }
$$

This fact is easily proved by using axiom (MTL1), Proposition 2(7) and Modus Ponens. Now, by Proposition 2(8), we have:

$$
\text { - }(\varphi(\mathrm{x}) \rightarrow \varphi(\mathrm{y})) \&(\varphi(\mathrm{y}) \rightarrow \varphi(\mathrm{x})) \rightarrow(\varphi(\mathrm{x}) \rightarrow \varphi(\mathrm{y})) \wedge(\varphi(\mathrm{y}) \rightarrow \varphi(\mathrm{x})),
$$

and

$$
\text { ' }(\psi(\mathrm{x}) \rightarrow \psi(\mathrm{y})) \&(\psi(\mathrm{y}) \rightarrow \psi(\mathrm{x})) \rightarrow(\psi(\mathrm{x}) \rightarrow \psi(\mathrm{y})) \wedge((\psi(\mathrm{y}) \rightarrow \psi(\mathrm{x})) .
$$

Consequently, by aplying the fact (4) to (3), (5) and (6), we obtain:

$\mathrm{T}^{\prime} \mathrm{x} \approx^{\mathrm{h}} \mathrm{y} \rightarrow[(\varphi(\mathrm{x}) \rightarrow \varphi(\mathrm{y})) \wedge(\varphi(\mathrm{y}) \rightarrow \varphi(\mathrm{x}))] \wedge[(\psi(\mathrm{x}) \rightarrow \psi(\mathrm{y})) \wedge((\psi(\mathrm{y}) \rightarrow \psi(\mathrm{x}))]$, and, by Proposition 2(9,10,11), we obtain:

$$
\begin{gathered}
\mathrm{T}^{-\mathrm{x}} \approx^{\mathrm{h}} \mathrm{y} \rightarrow \\
\rightarrow[(\varphi(\mathrm{x}) \rightarrow \varphi(\mathrm{y})) \wedge(\psi(\mathrm{x}) \rightarrow \psi(\mathrm{y}))] \wedge[(\varphi(\mathrm{y}) \rightarrow \varphi(\mathrm{x})) \wedge((\psi(\mathrm{y}) \rightarrow \psi(\mathrm{x}))] .
\end{gathered}
$$


Now consider the first part of the conjunction, that is,

$$
(\varphi(\mathrm{x}) \rightarrow \varphi(\mathrm{y})) \wedge(\psi(\mathrm{x}) \rightarrow \psi(\mathrm{y})) .
$$

Now, by applying Proposition 2(12), we obtain:

and

$$
(\varphi(\mathrm{x}) \rightarrow \varphi(\mathrm{y})) \rightarrow((\varphi(\mathrm{x}) \wedge \psi(\mathrm{x})) \rightarrow \varphi(\mathrm{y})),
$$

$$
\text { - }(\psi(\mathrm{x}) \rightarrow \psi(\mathrm{y})) \rightarrow((\varphi(\mathrm{x}) \wedge \psi(\mathrm{x})) \rightarrow \psi(\mathrm{y})) .
$$

Then, by applying Proposition 2(16,13), we have:

$$
\text { - }[(\varphi(\mathrm{x}) \rightarrow \varphi(\mathrm{y})) \wedge(\psi(\mathrm{x}) \rightarrow \psi(\mathrm{y}))] \rightarrow(\varphi(\mathrm{x}) \wedge \psi(\mathrm{x})) \rightarrow(\varphi(\mathrm{y}) \wedge \psi(\mathrm{y})),
$$

and proceeding in the same way with the other part of the conjunction in (7), that is, with $(\varphi(\mathrm{y}) \rightarrow \varphi(\mathrm{x})) \wedge((\psi(\mathrm{y}) \rightarrow \psi(\mathrm{x}))$, we obtain:

$$
\text { - }[(\varphi(\mathrm{y}) \rightarrow \varphi(\mathrm{x})) \wedge(\psi(\mathrm{y}) \rightarrow \psi(\mathrm{x}))] \rightarrow(\varphi(\mathrm{y}) \wedge \psi(\mathrm{y})) \rightarrow(\varphi(\mathrm{x}) \wedge \psi(\mathrm{x})) .
$$

We can conclude from (7), (8), (9), by using rule (4), that

$\left.\mathrm{T}^{-\mathrm{x}} \approx^{\mathrm{h}} \mathrm{y} \rightarrow[(\varphi(\mathrm{x}) \wedge \psi(\mathrm{x})) \rightarrow(\varphi(\mathrm{y}) \wedge \psi(\mathrm{y}))] \wedge[(\varphi(\mathrm{y}) \wedge \psi(\mathrm{y})) \rightarrow \varphi(\mathrm{x}) \wedge \psi(\mathrm{x}))\right]$

and, by definition of $\leftrightarrow$ and using Proposition 2(15), we have

$$
\mathrm{T}^{\wedge} \mathrm{x} \approx^{\mathrm{h}} \mathrm{y} \rightarrow[(\varphi(\mathrm{x}) \wedge \psi(\mathrm{x})) \leftrightarrow(\varphi(\mathrm{y}) \wedge \psi(\mathrm{y}))] .
$$

Inductive step $\left.\forall \mathrm{x}_{\mathrm{n}} \varphi\left(\mathrm{x}_{1}, \ldots, \mathrm{x}_{\mathrm{n}}\right)\right)$. In this step we will use the generalization to $\mathrm{n}$ variables of the proofs of the previous steps. By definition of the syntactic degree, $\operatorname{dg}\left(\forall \mathrm{x}_{\mathrm{n}} \varphi\left(\mathrm{x}_{1}, \ldots, \mathrm{x}_{\mathrm{n}}\right)\right)=\operatorname{dg}\left(\varphi\left(\mathrm{x}_{1}, \ldots, \mathrm{x}_{\mathrm{n}}\right)\right)=\mathrm{k}$. By inductive hypothesis we have

$$
\mathrm{T}^{-}\left(\mathrm{x}_{1} \approx^{\mathrm{k}} \mathrm{y}_{1}\right) \& \cdots \&\left(\mathrm{x}_{\mathrm{n}} \approx^{\mathrm{k}} \mathrm{y}_{\mathrm{n}}\right) \rightarrow\left(\varphi\left(\mathrm{x}_{1}, \ldots, \mathrm{x}_{\mathrm{n}}\right) \leftrightarrow \varphi\left(\mathrm{y}_{1}, \ldots, \mathrm{y}_{\mathrm{n}}\right)\right) .
$$

Our assumption implies (substituting $\mathrm{x}_{\mathrm{n}}$ for $\mathrm{y}_{\mathrm{n}}$ ),

$$
\begin{gathered}
\mathrm{T}^{-}\left(\mathrm{x}_{1} \approx^{\mathrm{k}} \mathrm{y}_{1}\right) \& \cdots \&\left(\mathrm{x}_{\mathrm{n}-1} \approx^{\mathrm{k}} \mathrm{y}_{\mathrm{n}-1}\right) \rightarrow \\
\rightarrow\left(\varphi\left(\mathrm{x}_{1}, \ldots, \mathrm{x}_{\mathrm{n}-1}, \mathrm{x}_{\mathrm{n}}\right) \leftrightarrow \varphi\left(\mathrm{y}_{1}, \ldots, \mathrm{y}_{\mathrm{n}-1}, \mathrm{x}_{\mathrm{n}}\right)\right) .
\end{gathered}
$$

Thus, by the generalization rule, we have

$$
\mathrm{T}-\forall \mathrm{x}_{\mathrm{n}}\left[\left(\mathrm{x}_{1} \approx^{\mathrm{k}} \mathrm{y}_{1}\right) \& \cdots \&\left(\mathrm{x}_{\mathrm{n}-1} \approx^{\mathrm{k}} \mathrm{y}_{\mathrm{n}-1}\right) \rightarrow\right.
$$




$$
\rightarrow\left(\varphi\left(\mathrm{x}_{1}, \ldots, \mathrm{x}_{\mathrm{n}-1}, \mathrm{x}_{\mathrm{n}}\right) \leftrightarrow \varphi\left(\mathrm{y}_{1}, \ldots, \mathrm{y}_{\mathrm{n}-1}, \mathrm{x}_{\mathrm{n}}\right)\right],
$$

and, since $\mathrm{x}_{\mathrm{n}}$ is not free in $\left(\mathrm{x}_{1} \approx^{\mathrm{k}} \mathrm{y}_{1}\right) \& \cdots \&\left(\mathrm{x}_{\mathrm{n}-1} \approx^{\mathrm{k}} \mathrm{y}_{\mathrm{n}-1}\right)$, we obtain:

$$
\begin{gathered}
\mathrm{T}^{-}\left(\mathrm{x}_{1} \approx^{\mathrm{k}} \mathrm{y}_{1}\right) \& \cdots \&\left(\mathrm{x}_{\mathrm{n}-1} \approx^{\mathrm{k}} \mathrm{y}_{\mathrm{n}-1}\right) \rightarrow \\
\rightarrow \forall \mathrm{x}_{\mathrm{n}}\left(\varphi\left(\mathrm{x}_{1}, \ldots, \mathrm{x}_{\mathrm{n}-1}, \mathrm{x}_{\mathrm{n}}\right) \leftrightarrow \varphi\left(\mathrm{y}_{1}, \ldots, \mathrm{y}_{\mathrm{n}-1}, \mathrm{x}_{\mathrm{n}}\right)\right),
\end{gathered}
$$

and then, by Proposition 3(1),

$$
\begin{gathered}
\mathrm{T}^{-}\left(\mathrm{x}_{1} \approx^{\mathrm{k}} \mathrm{y}_{1}\right) \& \cdots \& \mathrm{x}_{\mathrm{n}-1} \approx^{\mathrm{k}} \mathrm{y}_{\mathrm{n}-1} \rightarrow \\
\rightarrow\left(\forall \mathrm{x}_{\mathrm{n}} \varphi\left(\mathrm{x}_{1}, \ldots, \mathrm{x}_{\mathrm{n}}\right) \leftrightarrow \forall \mathrm{x}_{\mathrm{n}} \varphi\left(\mathrm{y}_{1}, \ldots, \mathrm{y}_{\mathrm{n}-1} \mathrm{x}_{\mathrm{n}}\right)\right) .
\end{gathered}
$$

Inductive step $\exists x_{n} \varphi\left(x_{1}, \ldots, x_{n}\right)$. In this step we will use also the generalization to $n$ variables of the proofs of the previous steps. By definition of the syntactic degree, $\operatorname{dg}\left(\exists \mathrm{x}_{\mathrm{n}} \varphi\left(\mathrm{x}_{1}, \ldots, \mathrm{x}_{\mathrm{n}}\right)\right)=\operatorname{dg}\left(\varphi\left(\mathrm{x}_{1}, \ldots, \mathrm{x}_{\mathrm{n}}\right)\right)=\mathrm{k}$. By inductive hypothesis we have

$$
\mathrm{T}^{-}\left(\mathrm{x}_{1} \approx^{\mathrm{k}} \mathrm{y}_{1}\right) \& \cdots \&\left(\mathrm{x}_{\mathrm{n}} \approx^{\mathrm{k}} \mathrm{y}_{\mathrm{n}}\right) \rightarrow\left(\varphi\left(\mathrm{x}_{1}, \ldots, \mathrm{x}_{\mathrm{n}}\right) \leftrightarrow \varphi\left(\mathrm{y}_{1}, \ldots, \mathrm{y}_{\mathrm{n}}\right)\right) .
$$

Our assumption implies that (substituting $\mathrm{x}_{\mathrm{n}}$ for $\mathrm{y}_{\mathrm{n}}$ ),

$$
\begin{gathered}
\mathrm{T}^{-}\left(\mathrm{x}_{1} \approx^{\mathrm{k}} \mathrm{y}_{1}\right) \& \cdots \&\left(\mathrm{x}_{\mathrm{n}-1} \approx^{\mathrm{k}} \mathrm{y}_{\mathrm{n}-1}\right) \rightarrow \\
\rightarrow\left(\varphi\left(\mathrm{x}_{1}, \ldots, \mathrm{x}_{\mathrm{n}-1}, \mathrm{x}_{\mathrm{n}}\right) \leftrightarrow \varphi\left(\mathrm{y}_{1}, \ldots, \mathrm{y}_{\mathrm{n}-1}, \mathrm{x}_{\mathrm{n}}\right)\right) .
\end{gathered}
$$

Thus, by the generalization rule, we have

$$
\begin{aligned}
& \mathrm{T}^{-} \forall \mathrm{x}_{\mathrm{n}}\left[\left(\mathrm{x}_{1} \approx^{\mathrm{k}} \mathrm{y}_{1}\right) \& \cdots \&\left(\mathrm{x}_{\mathrm{n}-1} \approx^{\mathrm{k}} \mathrm{y}_{\mathrm{n}-1}\right) \rightarrow\right. \\
& \rightarrow\left(\varphi\left(\mathrm{x}_{1}, \ldots, \mathrm{x}_{\mathrm{n}-1}, \mathrm{x}_{\mathrm{n}}\right) \leftrightarrow \varphi\left(\mathrm{y}_{1}, \ldots, \mathrm{y}_{\mathrm{n}-1}, \mathrm{x}_{\mathrm{n}}\right)\right],
\end{aligned}
$$

and, since $\mathrm{x}_{\mathrm{n}}$ is not free in $\left(\mathrm{x}_{1} \approx^{\mathrm{k}} \mathrm{y}_{1}\right) \& \cdots \&\left(\mathrm{x}_{\mathrm{n}-1} \approx{ }^{\mathrm{k}} \mathrm{y}_{\mathrm{n}-1}\right)$, we obtain:

$$
\begin{gathered}
\mathrm{T}^{-}\left(\mathrm{x}_{1} \approx^{\mathrm{k}} \mathrm{y}_{1}\right) \& \cdots \&\left(\mathrm{x}_{\mathrm{n}-1} \approx^{\mathrm{k}} \mathrm{y}_{\mathrm{n}-1}\right) \rightarrow \\
\rightarrow \forall \mathrm{x}_{\mathrm{n}}\left(\varphi\left(\mathrm{x}_{1}, \ldots, \mathrm{x}_{\mathrm{n}-1}, \mathrm{x}_{\mathrm{n}}\right) \leftrightarrow \varphi\left(\mathrm{y}_{1}, \ldots, \mathrm{y}_{\mathrm{n}-1}, \mathrm{x}_{\mathrm{n}}\right)\right),
\end{gathered}
$$

and then, by Proposition 3(2),

$$
\begin{gathered}
\mathrm{T}^{-}\left(\mathrm{x}_{1} \approx^{\mathrm{k}} \mathrm{y}_{1}\right) \& \cdots \&\left(\mathrm{x}_{\mathrm{n}-1} \approx^{\mathrm{k}} \mathrm{y}_{\mathrm{n}-1}\right) \rightarrow \\
\rightarrow\left(\exists \mathrm{x}_{\mathrm{n}} \varphi\left(\mathrm{x}_{1}, \ldots, \mathrm{x}_{\mathrm{n}}\right) \leftrightarrow \exists \mathrm{x}_{\mathrm{n}} \varphi\left(\mathrm{y}_{1}, \ldots, \mathrm{y}_{\mathrm{n}-1} \mathrm{x}_{\mathrm{n}}\right)\right) .
\end{gathered}
$$


It is well known that the description logic IALCE can be seen as a fragment of a first order fuzzy logic $[8,22,21]$. This logic, parametrized by a t-norm and denoted by $\Lambda^{*} \forall$, is the first order version of the propositional logic defined by evaluations over the structure determined on the real unit interval $[0,1]$ by a t-norm and its residua, extended with the standard involutive negation $\mathrm{N}(\mathrm{x})=1-\mathrm{x}$. This logic is an extension of the logic MTL $\sim \forall$. Nevertheless, Theorem 1 is not valid for MTL $\sim \forall$ as the following counterexample shows. On the other hand, for every description formula no containing the symbol $\sim$, the property expressed in the previous theorem holds.

Example 6. Take the Gödel algebra on $[0,1]$ expanded with the standard involutive negation $1-\mathrm{x}$. Observe that the propositional formula $\mathrm{p} \rightarrow(\mathrm{q} \leftrightarrow \mathrm{r})$ takes value 1 under the evaluation $\mathrm{e}(\mathrm{p})=0.3, \mathrm{e}(\mathrm{q})=0.5$, and $\mathrm{e}(\mathrm{r})=0.8$. However, under the same evaluation, the formula $\mathrm{p} \rightarrow(\sim \mathrm{r} \leftrightarrow \sim \mathrm{q})$ takes value 0.2 .

\section{Concluding Remarks and Future Work}

This work is a preliminary contribution on the direction of defining a Similarity Fuzzy Description Logic. We have introduced an SBox including axioms expressing properties of fuzzy equalities, allowing in this way models of the language with a non-geometrical interpretation of the similarity symbols. We have shown also that similar objects have similar properties, being these properties expressed by fuzzy description formulas evaluated in these objects. However, there are several interesting issues that have not been addressed in this paper and that will be the focus of our future research.

This paper is a first step in the study of the relationships between global and local similarities via aggregation operations. We begin by taking t-norms as aggregation operators and we define global similarities from local similarities by using t-norms. Since our primary focus is on integrating similarities in the context of Fuzzy Description Logics, we left for future work the extension of the results obtained in the present paper in the more general context of uninorms and other aggregation operators as OWA or some others with good compensator behaviour that we can found in the literature (see for instance [61]).

See also the work of Bobillo and Straccia on aggregation operators for fuzzy ontologies in [14]. In their article, they integrate fuzzy ontologies and aggregation operators they provide the syntax and semantics of a fuzzy Description Logic with fuzzy aggregation operators and a reasoning algorithm for the family of operators 
that are representable using a Mixed Integer Linear Programming optimization problem.

In an enough expressive language like SROIQ(D) [12], the axioms of reflexivity, symmetry, transitivity, and congruence can be expressed by using certain type of general inclusion axioms which can be included in the TBox, and a special kind of axioms called fuzzy role inclusion axioms, or fuzzy RIAs, which can be included in the so-called RBox (Role Box). The language SROIQ(D) includes role hierarchies, inverse roles, composition of roles among other features. In future work we would explore the possibility to extending the publicly available reasoner FUZZY DL (for a reference see [13]) to our logic or some fragments of it, as done in [12]. There, the authors build a tableaux using a set of satisfiability preserving rules which generate new simpler fuzzy assertion axioms together with some inequations over [0,1]-valued variables. Finally, an optimization problem through the set of inequations is solved. However, depending of the DL adopted, the logic will become undecidable. One interesting starting point could be to use Zadeh semantics.

The common approach to similarity (or dissimilarity) between objects is to define it by means of a distance measure. This implies, however, that objects are described geometrically, which is not always the case. In many situations objects are described symbolically and, in these cases, Tversky proposes to define similarity through the comparison of the features that describe these objects. In [62] Tversky shows situations in which similarities do not satisfy the usual mathematical properties of metrics. In [18] (see also [17]) Bouchon-Meunier et al. have developed a very broad notion of comparison compatible with the notions proposed by Tversky in [62]. This notion, called similitude is based on the concept of fuzzy measure. The similarity measures based on fuzzy measures are classified into three groups: measures of satisfiability, inclusion and resemblance. In this context, the notion of similarity based on a t-norm considered in this paper would be a special case of the more general notion of resemblance. As future work we will study the treatment of these general types of comparisons and the expression of its properties in the context of a SBox adapted to them.

In [20], Bĕhounek et al. study fuzzy relations in the graded framework of Fuzzy Class Theory (FCT) which generalizes existing crisp results on fuzzy relations to the graded framework. In [3] the relationship between global and local similarities in the graded framework of FCT was investigated. As a continuation of this work we plan to analyze the introduction in the SBox of these graded notions.

There are several works that we want to analyze since although they take a 
logical approach different than ours, we think that some of their ideas can be included in our framework. Similarity in DLs has been studied by Borgida et al. [16] and D'Amato et al. [26] among others, focusing on similarity measures between DL concepts. D'Amato et al. take as starting point the idea that measures for estimating concept similarity have to be able to appropriately consider concept semantics in order to correctly assess their similarity value. In accordance with this goal the authors propose a set of properties that a semantic similarity measure should have, analyze different extensional-based and intensional-based similarity measures proposed in the literature, and show that these approaches lack some of the needed properties. Finally, they define a measure for complex descriptions in some DL languages that is compliant with all of these criteria. Part of our future work will be devoted to the study of similarity between concepts in the fuzzy context following ideas proposed in $[16,26]$.

Sheremet et al. [55] propose an integration of logic-based and similarity-based approaches in classical DLs. They use concept constructors such as "in the rneighborhood" of C' where $\mathrm{r}$ is a positive rational number; or the operator $\mathrm{C} \Leftrightarrow \mathrm{D}$ which is interpreted by the set of all points in the similarity space that are closer to the instances of $\mathrm{C}$ than to the instances of $\mathrm{D}$. For example, it can be used to model statements like ' $\mathrm{X}$ resembles $\mathrm{C}$ more than D'.

In our formalism we can also express both, a notion of neighbourhood of a concept and a notion of comparative similarity between concepts (as in Sheremet et al. [55]). Given a concept $\mathrm{C}$, and a similarity role $\approx$, by using existential quantification, we define the concept $\exists \approx . C$ interpreted as a fuzzy set in the following way: for every $\mathrm{d} \in \Delta^{\mathbf{I}}$,

$$
(\exists \approx . C)^{\mathbf{I}}(\mathrm{d})=\sup \left\{(\mathrm{b} \approx \mathbf{I} d) * C^{\mathbf{I}}(b): b \in \Delta^{\mathbf{I}}\right\}
$$

Thus, given a rational number $r$, the $r$-neighbourhood of concept $C$ is the set of all $\mathrm{d} \Delta^{\mathbf{I}}$ such that $\left(\exists \approx .{ }^{\prime}\right)^{\mathbf{I}}(\mathrm{d})>\mathrm{r}$. Analogously, let $\mathrm{C}$ and $\mathrm{D}$ be two concepts. By using an implication concept constructor in the language interpreted as the residuum of a t-norm (see [36]), we define the concept $\exists \approx . C \rightarrow \exists \approx$.D interpreted as a fuzzy set as follows: for every $\mathrm{d} \in \Delta^{\mathbf{I}}$,

$$
(\exists \approx . \mathrm{C} \rightarrow \exists \approx . \mathrm{D})^{\mathbf{I}}(\mathrm{d})=(\exists \approx . \mathrm{C})^{\mathbf{I}}(\mathrm{d}) \rightarrow_{\star}(\exists \approx . \mathrm{D})^{\mathbf{I}}(\mathrm{d})
$$

Now, the elements $d \in \Delta^{\mathbf{I}}$ which are more similar (or equally similar) to $\mathrm{D}$ than to $\mathrm{C}$ are those for which $(\exists \approx . \mathrm{C} \rightarrow \exists \approx . \mathrm{D})^{\mathbf{I}}(\mathrm{d})=1$. 


\section{Acknowledgments}

First of all we would like to thank Francesc Esteva for his mentorship, he has introduced us to the study of mathematical fuzzy logic. His intelligence, courage and friendship is a model of collaborative research for all the Catalan logicians. This paper is a humble tribute to the research line he has recently developed, the study of logical foundations of fuzzy description logics in connection with mathematical fuzzy logic.

We also want to thank the reviewers of this paper and Lluís Godo for their valuable contributions. The authors acknowledge support by the Spanish MICINN project EdeTRI (TIN2012-39348-C02-01). The work of Armengol and Dellunde is also supported by the grant 2014SGR-118 from the Generalitat de Catalunya. Armengol is partially supported by the Spanish MICINN project COGNITIO (TIN2012-38450-C03-03); Dellunde by the Spanish MICINN project MILESS (TIN2013-45039-P); and Àngel García-Cerdaña by the Spanish MICINN project MTM 201125747, the CSIC project 201450E045, and the grant 2014SGR-788 from the Generalitat de Catalunya.

\section{References}

[1] I. Aguiló, J. Martín, G. Mayor, and Jaume Suñer. On distances derived from t-norms. Fuzzy Sets and Systems, 278:40-47, 2015.

[2] C. Alsina. On some metrics induced by copulas. In Wolfgang Walter, editor, General Inequalities 4, volume 71 of International Series of Numerical Mathematics, pages 397-397. Birkhüser Basel, 1984.

[3] E. Armengol, P. Dellunde, and À. García-Cerdaña. A logical study of local and global graded similarities. Applied Artificial Intelligence, 29:424-444, 2015 .

[4] F. Baader, D. Calvanese, D.L. McGuinness, D. Nardi, and P.F. PatelSchneider, editors. The Description Logic Handbook: Theory, Implementation, and Applications. Cambridge University Press, New York, NY, USA, 2003.

[5] F. Baader and P. Hanschke. A scheme for integrating concrete domains into concept languages. In IJCAI 1991: Proceedings of the Twelfth International Conference on Artificial Intelligence, pages 452-457, 1991. 
[6] F. Baader, I. Horrocks, and U. Sattler. Description logics. In F. van Harmelin, V. Lifshitz, and B. Porter, editors, Handbook of Knowledge Representation, pages $135-179$. Elsevier, 2008.

[7] F. Baader and C. Lutz. Description logic. In Patrick Blackburn, Johan van Benthem, and Frank Wolter, editors, The Handbook of Modal Logic, pages 757-820. Elsevier, 2006.

[8] F. Bobillo, M. Cerami, F. Esteva, À. García-Cerdaña, R. Peñaloza, and U. Straccia. Fuzzy Description Logics. In P. Cintula C. Fermüller and C. Noguera, editors, Handbook of Mathematical Logic, Volume 3, Studies in Logic. College Publications, London, 2015. Forthcoming.

[9] F. Bobillo, M. Delgado, J. Gómez-Romero, and U. Straccia. Fuzzy Description Logics under Gödel semantics. International Journal of Approximate Reasoning, 50(3):494-514, 2009.

[10] F. Bobillo and U. Straccia. Fuzzy description logics with general t-norms and datatypes. Fuzzy Sets and Systems, 160(23):3382-3402, 2009.

[11] F. Bobillo and U. Straccia. Supporting fuzzy rough sets in fuzzy description logics. In C. Sossai and G. Chemello, editors, Proceedings of ECSQARU 09: Symbolic and Quantitative Approaches to Reasoning with Uncertainty. 10th European Conference, volume 5590 of Lecture Notes on Artificial Intelligence, pages 676-687. Springer, 2009.

[12] F. Bobillo and U. Straccia. Generalized fuzzy rough description logics. Information Sciences, 189:43-62, 2012.

[13] Fernando Bobillo and Umberto Straccia. fuzzyDL: An expressive fuzzy description logic reasoner. In Proceedings of the 17th IEEE International Conference on Fuzzy Systems (FUZZ-IEEE 2008), IEEE Computer Society, pages 923-930. IEEE Xplore. Digital Library, 2008.

[14] Fernando Bobillo and Umberto Straccia. Aggregation operators for fuzzy ontologies. Applied Soft Computing, 13(9):3816-3830, 2013.

[15] D. Boixader, F. Esteva, and L. Godo. On the continuity of t-norms. In IFSA'99: Proceedings of the eighth International Fuzzy Systems Association world congress, pages

476-479, 1999. 
[16] A. Borgida, T. Walsh, and H. Hirsh. Towards measuring similarity in Description Logics. In I. Horrocks, U. Sattler, and F. Wolter, editors, Proceedings of the 2005 International Workshop on Description Logics (DL2005), volume 147 of CEUR Workshop Proceedings. CEUR-WS.org, 2005.

[17] B. Bouchon-Meunier, G. Coletti, M.J. Lesot, and M. Rifqi. Towards a conscious choice of a fuzzy similarity measure: A qualitative point of view. In E. Hüllermeier, R. Kruse, and F. Hoffman, editors, Computational Intelligence for Knowledge-Based Systems Design. Proceedings of IPMU 2011, volume 6178 of Lecture Notes in Computer Science, pages 1-10. Springer Berlin Heidelberg, 2010.

[18] B. Bouchon-Meunier, M. Rifqi, and S. Bothorel. Towards general measures of comparison of objects. Fuzzy Sets and Systems, 84:143-153, 1996.

[19] R. Bělohlávek. Fuzzy Relational Systems: Foundations and Principles. Number 20 in International Series on Systems Science and Engineering. Kluwer Academic / Plenum Press, 2002.

[20] L. Běhounek, U. Bodenhofer, and P. Cintula. Relations in Fuzzy Class Theory. Fuzzy Sets and Systems, 159(14):1729-1772, 2008.

[21] M. Cerami, À. García-Cerdaña, and F. Esteva. On the relations between fuzzy description logics and multi-valued modal logics. Forthcoming.

[22] M. Cerami, À. García-Cerdaña, and F. Esteva. On finitely-valued Fuzzy Description Logics. International Journal of Approximate Reasoning, 55(9):1890 - 1916, 2014. Special Issue: Weighted Logics for Artificial Intelligence.

[23] R. Cignoli, F. Esteva, L. Godo, and A. Torrens. Basic fuzzy logic is the logic of continuous t-norms and their residua. Soft Computing, 4(2):106-112, 2000 .

[24] P. Cintula and P. Hájek. Triangular norm based predicate fuzzy logics. Fuzzy Sets and Systems, 161:311-346, 2010.

[25] H. S. M. Coxeter and S. L. Greitzer. Geometry Revisited. Mathematical Association of America, Washington, DC, 1967. 
[26] C. D'Amato, S. Staab, and N. Fanizzi. On the influence of description logics ontologies on conceptual similarity. In A. Gangemi and J. Euzenat, editors, EKAW '08: Proceedings of the 16th international conference on Knowledge Engineering, pages 48-63. Springer-Verlag, Berlin, Heidelberg, 2008.

[27] M. Detyniecki. Fundamentals on aggregation operators. Technical report, Computer Science Division. Universiyty of California, Berkeley, 2001.

[28] D. Dubois and H. Prade. The three semantics of fuzzy sets. Fuzzy Sets and Systems, 90(2):141-150, 1997.

[29] D. Dubois and H. Prade. On the use of aggregation operations in information fusion process. Fuzzy Sets and Systems, 142:143-161, 2004.

[30] R. Ertola, F. Esteva, T. Flaminio, L. Godo, and C. Noguera. Paraconsistency properties in degree-preserving fuzzy logics. Soft Computing, 19:531-546, 2015.

[31] F. Esteva and L. Godo. Monoidal t-norm based logic: towards a logic for left-continuous t-norms. Fuzzy Sets and Systems, 124:271-288, 2001.

[32] J Fodor, R. Yager, and A. Rybalov. Structure of uninorms. International Journal of Uncertainty, Fuzziness and Knowlegge-based Systems, 5:411427, 1997.

[33] P. Forrest. The Identity of Indiscernibles. The Stanford Encyclopedia of Philosophy (Winter 2012 Edition), Edward N. Zalta (ed.). http://plato.stanford.edu/archives/win2012/entries/identity-indiscernible/.

[34] À. García-Cerdaña, E. Armengol, and F. Esteva. Fuzzy description logics and t-norm based fuzzy logics. International Journal of Approximate Reasoning, 51(6):632-655, 2010.

[35] P. Hájek. Metamathematics of Fuzzy Logic, volume 4 of Trends in Logic. Studia Logica Library. Kluwer Academic Publishers, Dordrecht, 1998.

[36] P. Hájek. Making fuzzy description logic more general. Fuzzy Sets and Systems, 154(1):1-15, 2005.

[37] http://www.ncbi.nlm.nih.gov/taxonomy. 
[38] E. Hüllermeier. Case-Based Approximate Reasoning, volume 44 of Theory and Decision Library. Springer-Verlag, 2007.

[39] A. K. Jain, M. N. Murty, and P. J. Flynn. Data clustering: A review. ACM Computing Surveys (CSUR), 31(3):264-323, September 1999.

[40] S. Jenei and F. Montagna. A proof of standard completeness for Esteva and Godo's logic MTL. Studia Logica, 70(2):183-192, 2002.

[41] E.P. Klement, R. Mesiar, and E. Pap. Triangular Norms, volume 8 of Trends in Logic. Studia Logica Library. Kluwer Academic Publishers, Dordrecht, 2000 .

[42] D. Kudenko and H. Hirsh. Feature-based learners for description logics. In P. Lambrix, A. Borgida, Lenzerini, M., and R. Möller, editors, Proceedings of the 1999 International Workshop on Description Logics (DL'99), volume 22 of CEUR Workshop Proceedings. CEUR, 1999.

[43] T. W. Liao, Z. Zhang, and C. Mount. Similarity measures for retrieval in case-based reasoning systems. Applied Artificial Intelligence, 12(4):267$288,1998$.

[44] C. Ling. Representation of associative functions. Publicationes Mathematicae Debrecen, 12:189-212, 1965.

[45] T. Lukasiewicz and U. Straccia. Managing uncertainty and vagueness in Description Logics for the Semantic Web. Journal of Web Semantics, 6(4):291-308, 2008.

[46] C. Lutz. The Complexity of Description Logics with Concrete Domains. $\mathrm{PhD}$ thesis, LuFG Theoretica Computer Science, RWTH Aachen, Germany, 2002.

[47] C. Lutz. Description logics with concrete domains-a survey. In P. Balbiani, N.Y. Suzuki, F Wolter, and M. Zakharyaschev, editors, Advances in Modal Logic, Volume 4, pages 265-296. King's College Publications, 2003.

[48] G. Mayor and J. Torrens. On a class of operators for expert systems. International Journal of Intelligent Systems, 8:771-778, 1993. 
[49] G. Mayor and J. Torrens. Triangular norms in discrete settings. In E.P. Klement and R. Messiar, editors, Logical, Algebraic, Analytic, and Probabilistic Aspects of Triangular Norms, pages 189-230. Elsevier, Amsterdam, 2005.

[50] T. Calvo. G. Mayor and R. Mesiar, editors. Aggregation operators: new trends and applications, volume 97. Physica-Verlag, Heidelberg, 2002.

[51] P. S. Mostert and A. L. Shields. On the structure of semigroups on a compact manyfold with boundary. Annals of Mathematics, 65:117-143, 1957.

[52] Y. Ouyang. A note on metrics induced by copulas. Fuzzy Sets and Systems, 191:122-125, 2012.

[53] J. Recasens. Indistinguishability Operators - Modelling Fuzzy Equalities and Fuzzy Equivalence Relations, volume 260 of Studies in Fuzziness and Soft Computing. Springer, 2011.

[54] E. H. Ruspini. On the semantics of fuzzy logics. International Journal of Approximate Reasoning, 5:45-88, 1991.

[55] M. Sheremet, D. Tishkovsky, F. Wolter, and M. Zakharyaschev. A logic for concepts and similarity. Journal of Logic and Computation, 17(3):415-452, 2007.

[56] G. Stoilos, G. Stamou, J.Z. Pan, V. Tzouvaras, and I. Horrocks. Reasoning with very expressive Fuzzy Description Logics. Journal of Artificial Intelligence Research, 30(8):273-320, 2007.

[57] U. Straccia. Reasoning within Fuzzy Description Logics. Journal of Artificial Intelligence Research, 14:137-166, 2001.

[58] U. Straccia. Description logics with fuzzy concrete domains. In Fahiem Bachus and Tommi Jaakkola, editors, 21st Conference on Uncertainty in Artificial Intelligence (UAI-05), pages 559-567, Edinburgh, Scotland, 2005. AUAI Press.

[59] U. Straccia. A Fuzzy Description Logic for the Semantic Web. In Elie Sanchez, editor, Fuzzy Logic and the Semantic Web, Capturing Intelligence, chapter 4, pages 73-90. Elsevier, 2006.

[60] U. Straccia. Foundations of Fuzzy Logic and Semantic Web Languages. CRC Studies in Informatics Series. Chapman \& Hall, 2013. 
[61] V. Torra and Y. Narukawa. Modeling decisions - information fusion and aggregation operators. Springer, 2007.

[62] A. Tversky. Features of similarity. Psychological Review, 84(4):327-352, 1977.

[63] Y. Yang, G.I. Webb, and X. Wu. Discretization methods. In Oded Maimon and Lior Rokach, editors, Data Mining and Knowledge Discovery Handbook, pages 113-130. Springer US, 2005.

[64] L. A. Zadeh. Similarity relations and fuzzy orderings. Information Sciences, 3:177-200, 1971. 